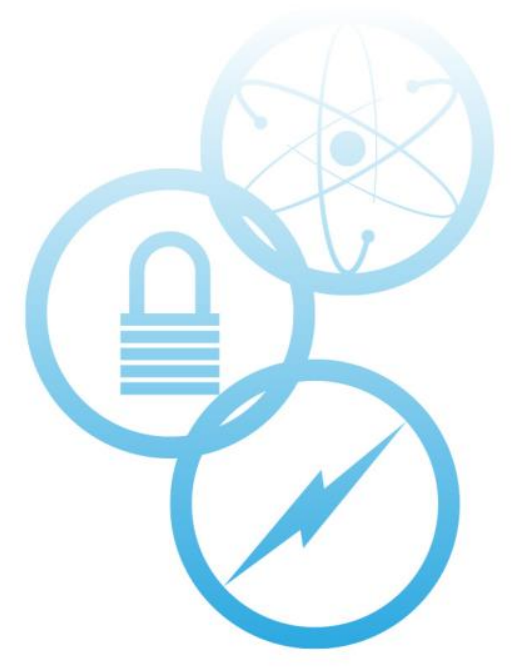

Net-zero Microgrid Program Project Report:

\title{
Small Reactors in Microgrids
}

\section{October 2021}

\section{Technical Studies Guidance}

Bikash Poudel, Timothy McJunkin, and Ning Kang

Idaho National Laboratory

James T. Reilly

Reilly Associates

The Net-Zero Microgrid Program provides cross-cutting research to accelerate the use of renewable and zero-carbon generation in microgrids.

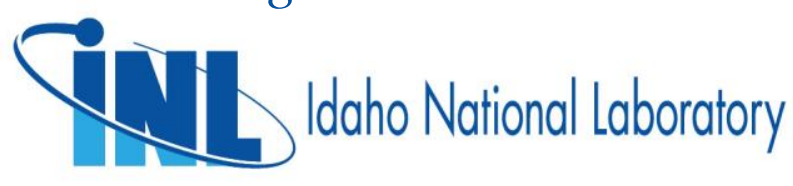




\section{DISCLAIMER}

This information was prepared as an account of work sponsored by an agency of the U.S. Government. Neither the U.S. Government nor any agency thereof, nor any of their employees, makes any warranty, expressed or implied, or assumes any legal liability or responsibility for the accuracy, completeness, or usefulness, of any information, apparatus, product, or process disclosed, or represents that its use would not infringe privately owned rights. References herein to any specific commercial product, process, or service by trade name, trade mark, manufacturer, or otherwise, does not necessarily constitute or imply its endorsement, recommendation, or favoring by the U.S. Government or any agency thereof. The views and opinions of authors expressed herein do not necessarily state or reflect those of the U.S. Government or any agency thereof. 


\title{
Net-zero Microgrid Program Project Report: Small Reactors in Microgrids
}

\author{
Technical Studies Guidance
}
Bikash Poudel, Timothy McJunkin, and Ning Kang
Idaho National Laboratory
James T. Reilly
Reilly Associates

October 2021

\section{Idaho National Laboratory \\ Energy and Environment Science and Technology Idaho Falls, Idaho 83415}

http://www.inl.gov

\author{
Prepared for the \\ U.S. Department of Energy \\ Office of Electricity \\ Under DOE Idaho Operations Office \\ Contract DE-AC07-05ID14517
}


Page intentionally left blank 


\section{EXECUTIVE SUMMARY}

This report presents several design configurations of small reactor (SR)based microgrids for the deployment in different use case applications. In general, the proposed microgrids are designed with SRs that include small modular reactors (SMRs) and microreactors, distributed renewable generation in the form of wind and photovoltaics and battery energy-storage systems. Most configurations include generation centralized at one location, which is typically at a microgrid center or near the substation connecting to the utility grid. Some applications, such as remote communities with sparsely distributed load demand over a larger area, may have microgrid generation assets decentralized within the larger microgrid boundary. Microgrid configurations can have either an alternating- or direct-current distribution system, depending on the application. The configurations using both heat and electricity products may also include thermal energy storage to support the heating-side supply and demand management. Similarly, configurations supporting critical life functions, as in space microgrids, include a high level of generation redundancy and dedicated energy storage for each load function. Microgrid configurations have their respective design principles, with different priorities for power and energy adequacy, system economics, system reliability and operational resilience while not straying from the Net-Zero objective.

Power-system engineering issues are identified for the design of a microgrid with an SR as part of the generation mix, and interoperability with distributed energy resources, including (thermal or electrical) storage within the microgrid. For each microgrid configuration, several priority studies are considered to evaluate the planning and operational feasibility for the deployment of microgrids with SRs that include siting, sizing of the generation assets, and their design and operation.

Finally, technoeconomic models are developed for SRs to enable highpriority feasibility studies for different microgrid configurations, optimized for overall system performance and economics. A thorough review of the literature was conducted as part of the SR microgrid project. Analysis based on the literature was used to predict and extrapolate the characteristic ways SR technology will function as part of the grid and, specifically, microgrids. Key data points related to the economic and operational performance of SRs sized 0.1-20 MW were identified, and metrics for SRs were estimated. Quantitative input for the technoeconomic model will come from the refinement of these estimates as the study of SRs in microgrids continues. Data from these estimates and laboratory studies are intended to be used in the XENDEE platform for 
microgrid decision-making. Considerable work needs to be done in this area because empirical data on the operational characteristics of SRs in microgrids are not fully known and have not yet been modeled dynamically.

The report is organized into five sections and three annexes. Section 1, Guidance for Studies Required for Microgrids Considering Small Reactors as an Energy Source, establishes a set of case studies for which we anticipate incorporating SRs as a cornerstone of power and grid services in a microgrid will be of large benefit in providing resilience and greenhouse-gas reduction. Each case study represents either a unique or a class of opportunity for the application of microgrids. The necessary steps to study the proposed SR microgrids from concept to detailed design that is ready for construction are described. The discussion is at a high level but will be more completely detailed in future efforts within the SR projects that are part of the Net-Zero Microgrid (NZM) Program. Examples of microgrid applications are given (see Section 2).

Section 3 explores the studies necessary to evaluate the feasibility of SRbased microgrid applications. Technoeconomic Model and Cost Analysis of SR, Section 4, estimates cost and capabilities datapoints to develop technoeconomic model for SRs. Specifically, this development is targeted at exploring microgrid design tools using the XENDEE platform. Section 5, SR Microgrid ProjectNext Steps, provides concluding remarks along with the summary of proposed future work.

Annex A provides a detailed literature study exploring the cost and capabilities of existing nuclear power plants and upcoming SRs to extrapolate technoeconomic models for SRs. Annex B provides the list of current SR concepts suitable for the microgrid applications proposed in this report. Annex C provides a summary of the NZM Program purpose and objectives. SR microgrids play a pivotal role in the reduction of the carbon footprint of microgrids and, thus, make a major contribution to the overall goal of a net-zero-carbon economy for the U.S.

This report advances SR as a carbon-free energy source for generation in microgrids, which supports the cross-cutting objectives of the Department of Energy, Office of Electricity's NZM Program to replace carbon fuel-based generation that is prevalent in today's microgrids. 


\section{ACKNOWLEDGMENTS}

We thank Dan Ton, Program Manager for the DOE Office of Electricity Microgrid Program for supporting the effort that produced this report. In addition, we appreciate the comments, and conversations with Shannon BraggSitton, National Technical Director for DOE-NE Office of Nuclear Energy's Integrated Energy System program, John Jackson, National Technical Director for DOE-NE Office of Nuclear Energy's Microreactor program and Kurt Myers, Senior Microgrid Researcher, that greatly improved this report. 


\section{CONTENTS}

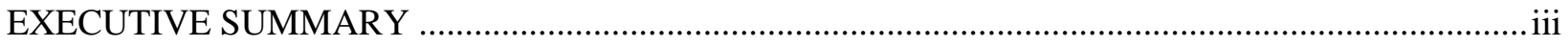

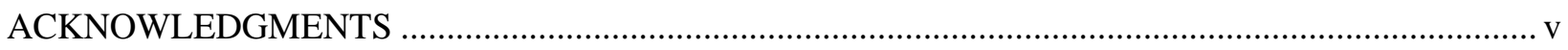

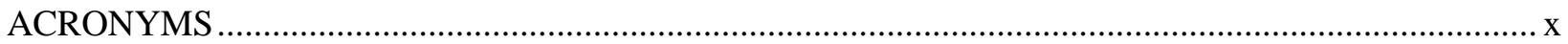

1. GUIDANCE FOR STUDIES REQUIRED FOR MICROGRIDS CONSIDERING SMALL REACTORS AS AN ENERGY SOURCE ...................................................................... 1

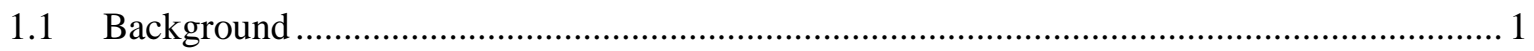

2. PROPOSED MICROGRID APPLICATIONS OF SMALL REACTORS ...................................... 3

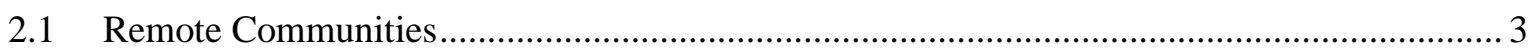

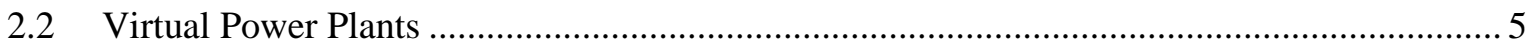

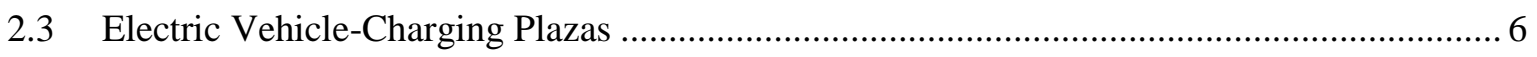

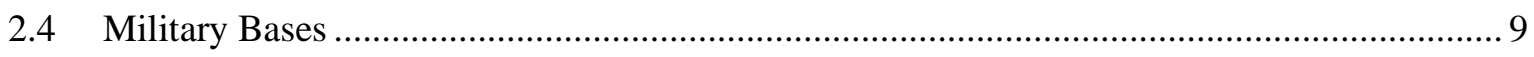

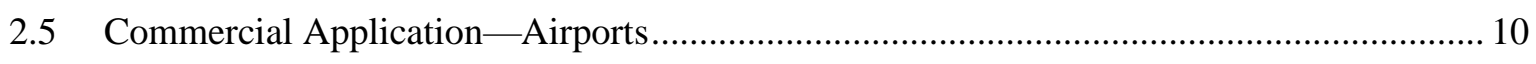

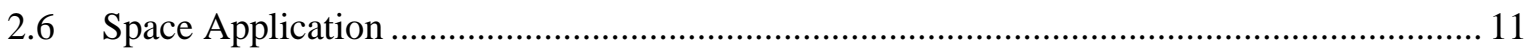

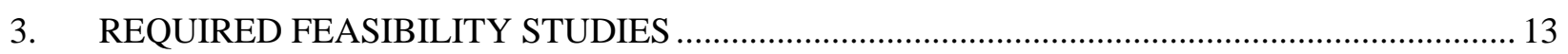

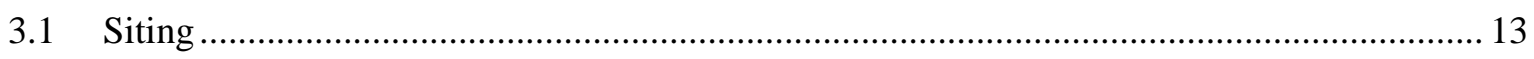

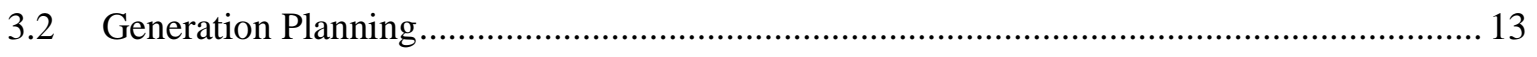

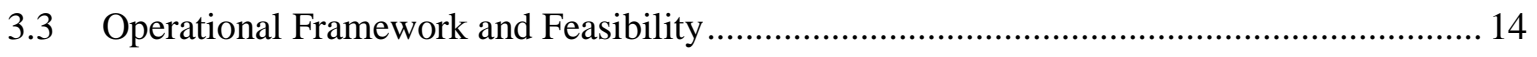

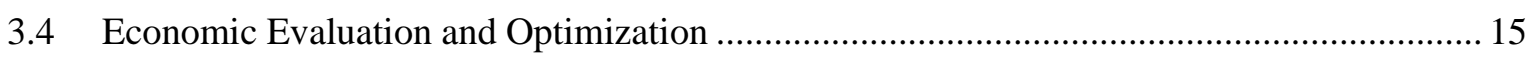

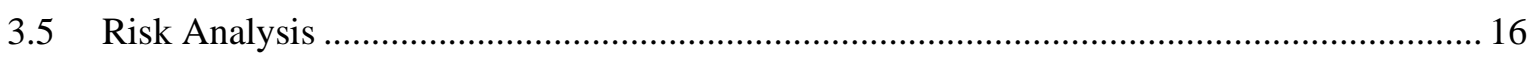

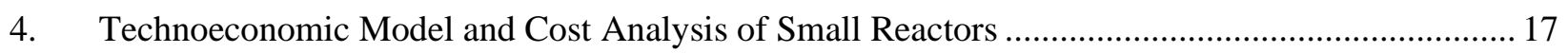

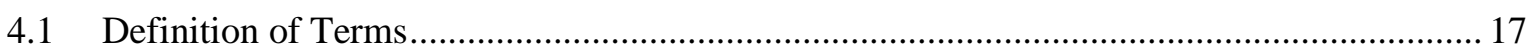

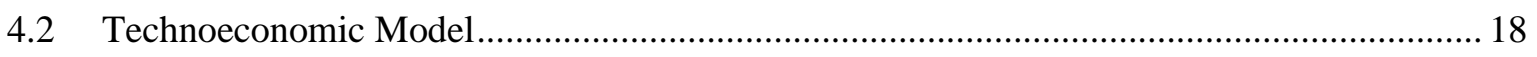

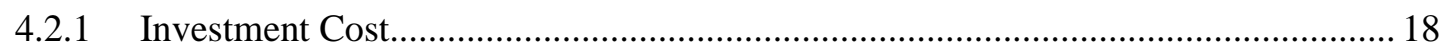

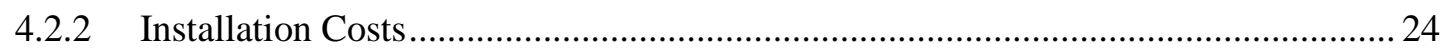

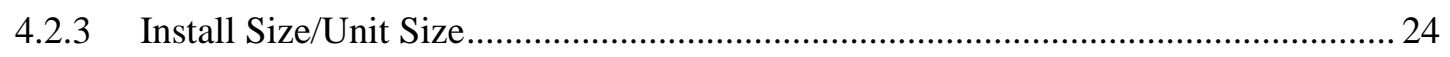

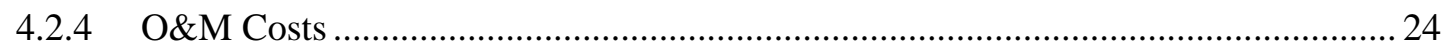

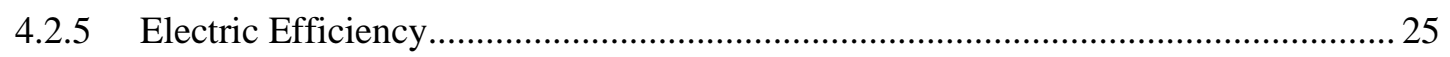

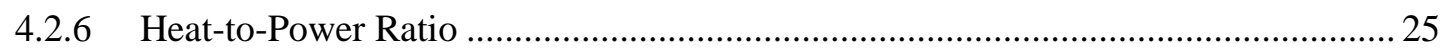

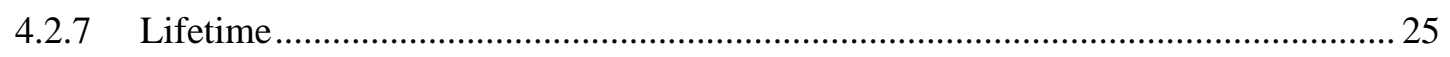

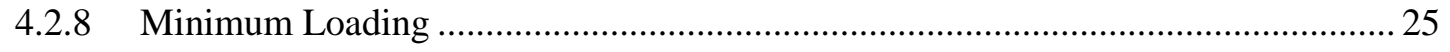

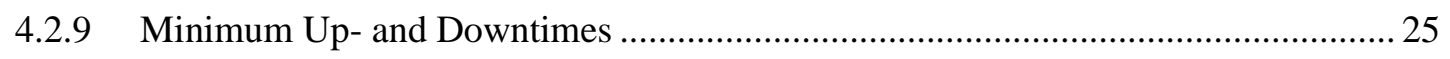

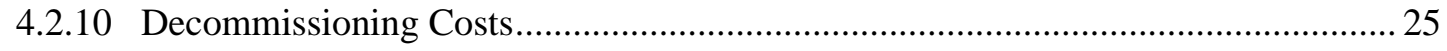

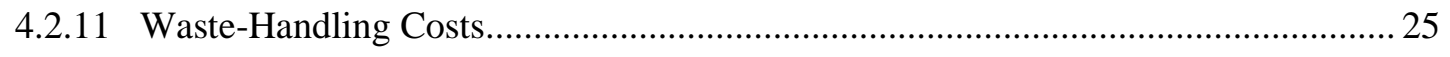

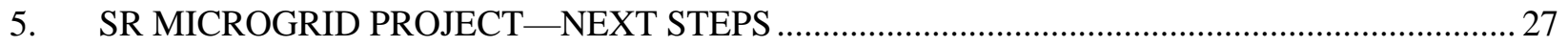

5.1 Next Steps in Realizing the Potential of SR Microgrids and the Realization of ZeroCarbon Goals. 


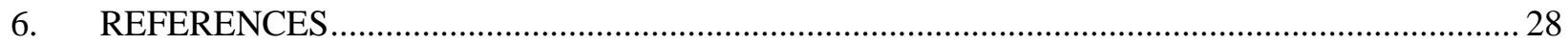

Annex A Literature Study for SR Technoeconomic Modeling ............................................................ 33

Annex B List of Small Modular Reactor (SMR) and Microreactor Concepts Potentially Suitable for Microgrid Applications ................................................................................................ 49

Annex C Net-Zero Microgrid Program................................................................................................ 55

\section{FIGURES}

Figure 1. Using SRs with DERs in remote communities, which includes the option of more feeder-specific storage based on the cost and desired reliability/resilience. ............................... 4

Figure 2. Integrated heat-electricity network in remote communities................................................... 5

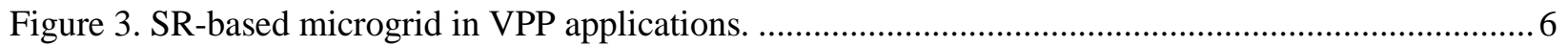

Figure 4. SRs in a microgrid with PVs for an EV charging station. .................................................... 8

Figure 5. An HV fueling station added to the EV charging station for an integrated EV/HV

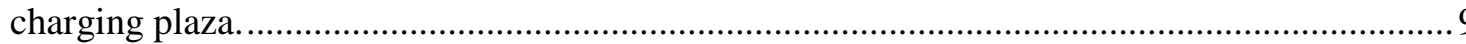

Figure 6. SR-based microgrid for a military base. The military microgrid may host local DERs and also connect with nearby renewables farms and isolated communities............................. 10

Figure 7. SR-based microgrid for commercial application in airports.

Figure 8. An SR-based microgrid for space application where the critical loads are life-safety functions; on an inhabited station, most loads are mission-critical, but there may be some non-life-safety or mission-configurable loads that would be flexible.

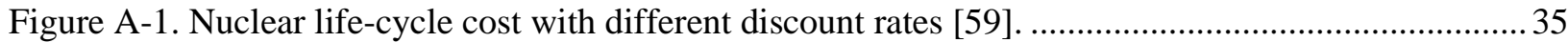

Figure A-2. Cost factors to be considered while scaling down investment cost from large reactors. ........ 40

Figure A-3. Limits proposed for SRs in [47]: Basic (A), Advanced (B) and Extreme (C)...................... 47

\section{TABLES}

Table 1. Definition of the terms used in technoeconomic modeling. .................................................... 17

Table 2. Cost components in nuclear power plants (as a percentage of $300 \mathrm{MW}$ plant).........................19

Table 3. Cost components in nuclear power plants (in millions of dollars) .............................................20

Table 4. Cost components of SRs (based on old scaling factors). ........................................................20

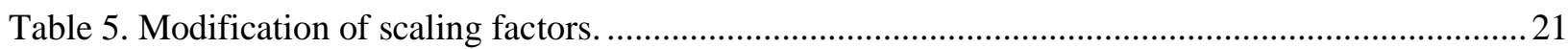

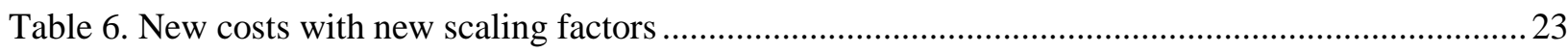

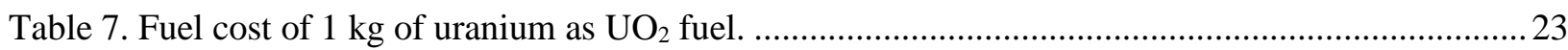

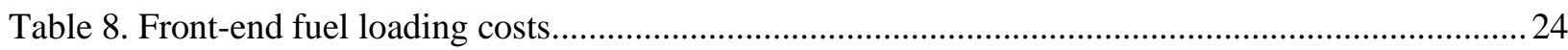

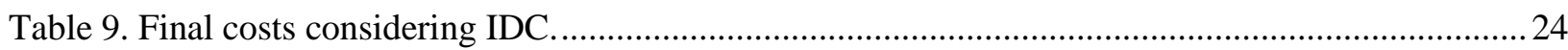

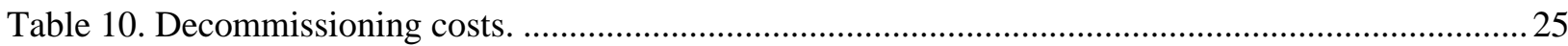




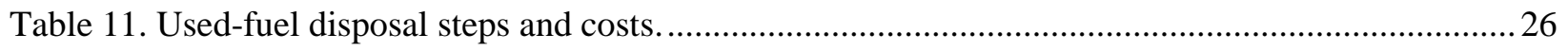

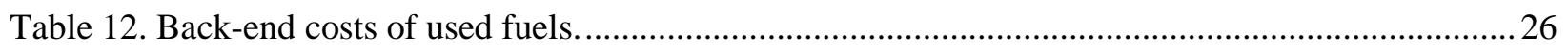

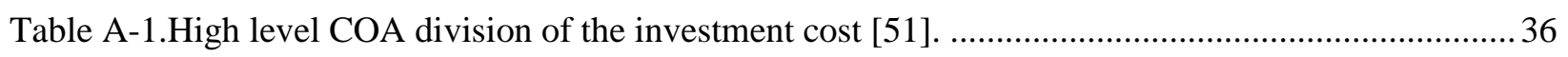

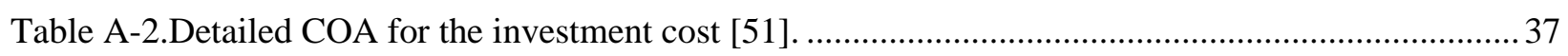

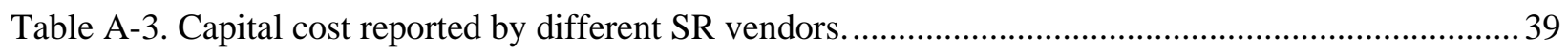

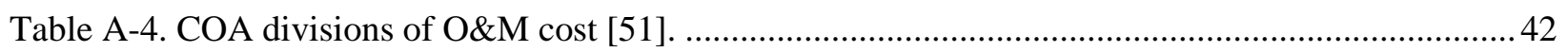

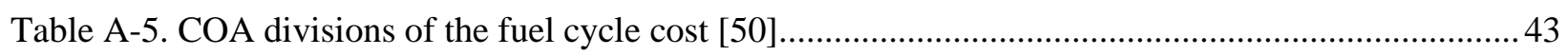

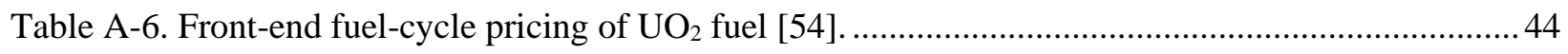

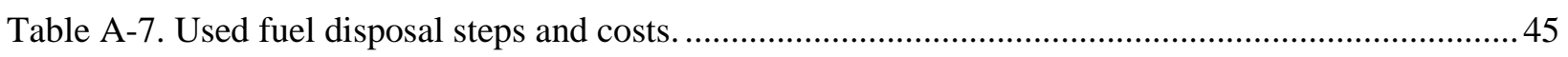

Table B-1. SMR and microreactor concepts potentially suitable for microgrid applications....................51 
Page intentionally left blank 


\section{ACRONYMS}

\begin{tabular}{|c|c|}
\hline ABWR & advanced boiling water reactor \\
\hline $\mathrm{AC}$ & alternating current \\
\hline BESS & battery energy-storage system \\
\hline CAREM & Central Argentina de Elementos Modulares \\
\hline $\mathrm{COA}$ & Code of Account \\
\hline DC & direct current \\
\hline DER & distributed energy resource \\
\hline DGR & deep geologic repository \\
\hline DOE & Department of Energy \\
\hline DSO & distribution system operator \\
\hline EPC & engineering, procurement, and construction \\
\hline EV & electric vehicle \\
\hline FOAK & first of a kind \\
\hline FOAKE & first of a kind engineering \\
\hline GHG & greenhouse gas \\
\hline GIF & Gen IV International Forum \\
\hline HTE & high-temperature electrolysis \\
\hline HTGR & high-temperature gas-cooled reactor \\
\hline IAEA & International Atomic Energy Agency \\
\hline IDC & interest during construction \\
\hline INL & Idaho National Laboratory \\
\hline ISS & International Space Station \\
\hline $\mathrm{HV}$ & hydrogen vehicle \\
\hline LCOE & levelized cost of electricity \\
\hline LWR & light-water reactor \\
\hline MAGNET & Microreactor Agile Non-nuclear Experimental Testbed \\
\hline MARVEL & Microreactor Applications Research Validation and Evaluation \\
\hline NEA & Nuclear Energy Agency \\
\hline NERAC & Nuclear Energy Research Advisory Committee \\
\hline NEST & Nuclear Energy System Assessment Economic Support Tool \\
\hline NOAK & nth-of-a-kind \\
\hline NPP & nuclear power plant \\
\hline NRC & Nuclear Regulatory Commission \\
\hline
\end{tabular}


NZM Net-Zero Microgrid (Program)

OC operating cost

OE (DOE) Office of Electricity

OECD Organisation for Economic Co-operation and Development

O\&M operations and maintenance

PV photovoltaic

REO rated electrical output

SMR small modular reactor

SR small reactor

SWU separate work units

TCIC total capital investment cost

TREAT Transient Reactor Test Facility

TRL technology readiness level

TSO transmission system operator

UAMPS Utah Associated Municipal Power Systems

VPP virtual power plant 
Page intentionally left blank 


\title{
Net-zero Microgrid Program Project Report:
}

\author{
Small Reactors in Microgrids
}

\section{GUIDANCE FOR STUDIES REQUIRED FOR MICROGRIDS CONSIDERING SMALL REACTORS AS AN ENERGY SOURCE}

This section captures the studies that are required to understand the requirements for integrating small reactors (SRs) in microgrid applications. The use cases that are provided span a range of microgrid configurations that serve particular "customers" within their boundaries.

Generation from SRs offers two special advantages: 1) an increase in resilience resulting from removing supply constraints on the feedstock of fuel, like traditional diesel and natural gas, that overwhelmingly dominate in microgrids today and 2) integration with renewable generation, storage, and flexible loads in these microgrid applications, which would markedly reduce greenhouse gases (GHGs), moving towards a goal of zero-carbon.

\subsection{Background}

Scientific evidence shows that the extreme weather events arising from global warming are worsening day by day adversely impacting the resiliency and integrity of electrical grids [1][2]. The rapid shift towards clean generation technologies, such as wind and photovoltaics (PVs), has further worsened the resilience of the electrical grid due to the increased generation uncertainty and intermittency.

Microgrids as defined by IEEE Standard for Specification of Microgrid Controllers, IEEE 2030.72017[3]:

A group of interconnected loads and distributed energy resources with clearly defined electrical boundaries that act as a single controllable entity with respect to the grid and can connect and disconnect from the grid to enable it to operate in both grid-connected and island modes.

In addition to their traditional use in communities and industries isolated and far from the central grid structure, microgrids are increasingly considered as an integral component of the electrical grid to which they are connected. The connection allows the two-way exchange of power. Microgrids can decentralize larger grids into smaller entities, each capable of sustaining themselves without supply from the grid by aggregating local distributed resources and with support from energy-storage technologies. Depending upon the availability of reliable generation sources, microgrids can be made immune to grid loss arising from the loss of weak transmission infrastructure or due to extreme weather events. While microgrids are increasingly adopted by commercial and industrial facilities and military bases irrespective of gridconnection availability, their eventual adoption in future applications, such as charging plazas and extraterrestrial stations, is widely accepted. The scale of microgrids can vary widely by application dependent on the critical functions to be supported when islanding is required and the investment in generation assets made by microgrid owners/operators to support those critical functions and/or to supply power and energy or other services to the connected utility. Applications highlighted in this report range from tens of kilowatts to hundreds of megawatts; however, there are no hard lower and upper limits set by the definition of a microgrid. Currently, distributed wind and PV generators are central to microgrid architecture due to their cost-effectiveness and scalability, but their operation as nondispatchable generation and intrinsic variability generation means that there is a need for a scalable and reliable clean generation to complement their shortcomings for sustainable microgrids.

The use of SRs, which include modular and microreactors, in microgrids has received significant research interest due to their smaller size, compact and long-lasting fuel, ease of transportation and 
assembly, flexible siting, improved safety features, and improved flexible operation capabilities [4]. The SR generations that would be of interest to the scale microgrids referenced in this report range from $100 \mathrm{~kW}$ to $20 \mathrm{MW}$ that would be encompassed by reactors referred to as microreactors and small modular reactors (SMRs). For microgrid applications, SRs designs that are manufactured in a factory setting and can be transported in a commission ready form to the microgrid by truck, rail, or air transportation are of most interest. SRs are typically designed with long-lasting fuels. Once loaded, the reactor fuel can last from 5 to 30 years, which is a major advantage of SRs over diesel generators, which, apart from their large carbon emissions, face difficulties in fuel transportation during extreme weather events [5]. SRs are designed to be inherently safe and accident-tolerant due to features such as simpler integral designs, passive coolant circulation, containment, and shutdown systems and underwater/underground configurations [4][6]. Further, the potential of SRs to provide heat along with electricity enhances their economic potential and adds value from flexible-operation capability, adding more impetus towards achieving carbon-reduction goals.

SRs are being developed in all major technological lines of reactors, including water-cooled reactors, high-temperature gas-cooled reactors, fast-neutron reactors, and molten-salt reactors [4]. Annex B lists some of the SR technologies suitable for the microgrid applications proposed in this project. The Microreactor Applications Research Validation and Evaluation (MARVEL) microreactor project, supported by the U.S. Department of Energy (DOE), will be one of the first SRs in the U.S. and will be developed at Idaho National Laboratory (INL) and installed at the Transient Reactor Test Facility (TREAT). MARVEL is a 100-kWt fission reactor that will enable the testing of several new nontraditional nuclear microgrid applications [7]. The Micro Modular Reactor is another SR project in Canada, to be hosted at the Chalk River Laboratories site. It is a joint venture between the Ultra Safe Nuclear Corporation and Ontario Power Generation that aims to site a plant by 2026 [4]. Several other SR technologies are under development and are expected to start operation by the late 2020s for demonstration purposes [7]-[10]. For practical use in microgrids in the first few years of production, SRs will need financial incentives to compete with other clean-energy generation [8]. As the technology matures and moves into factory production, SRs are expected to become economically competitive with other sources of clean generation. SRs can work with other forms of clean generation to develop sustainable energy microgrids. To this end, this research aims to explore various use cases of SR-based microgrids and develop a framework for potential studies required to understand their feasibility. 


\section{PROPOSED MICROGRID APPLICATIONS OF SMALL REACTORS}

Major applications of SRs include the provision of clean energy to remote communities, transportation charging plazas, commercial and industrial facilities, space stations, and critical infrastructures such as defense installations and emergency-response facilities. In this section, several of these SR-based microgrid use cases are explored, with the discussion primarily focused on design configurations, power distribution networks, synergy with renewables, the role of energy storage, and cogeneration opportunities.

\subsection{Remote Communities}

Remote communities, such as the ones located in the rural parts of Alaska, Guam, or northern Canada, face significant challenges to deliver clean, reliable, and affordable electrical power to their consumers [11][12]. The challenges to remote communities include the lack of infrastructure for a continuous supply of fuel, limited conventional energy resources, and a low level of economic activity coupled with low population density. Due to the low consumer density, the extension of long transmission feeders from the utility grid to off-grid communities is cost prohibitive, if even possible. Similarly, remote communities with existing weak connections face voltage and reliability challenges due to power transfer over long distances. Transmission losses are also typically very large. These remote communities in weakly connected parts of electrical grids or off-grid locations rely on diesel generators as their primary source of power. SRs present a unique opportunity to displace diesel generators in remote communities and develop sustainable clean-energy solutions. With reliable power from SRs, remote communities can host local distributed energy resources (DERs) such as wind and PVs in microgrids. Further, SRs can provide both electricity and heat to meet the heating needs of remote communities.

Figure 1 shows a microgrid configured for a remote community. The primary objective is to build sustainable, standalone, clean local-generation capacity to reduce reliance on diesel generators or a weak utility connection. The system load is in the range of 10-20 MW. The proposed microgrid system should be able to fulfill electricity requirements without relying on utility-grid supply. A single- or multimodule SR plant, of size 10-20 MW, is hosted at the substation level to provide reliable generation. Alternatively, multiple smaller microreactors could be hosted at the primary substation instead of large SR units. A centralized battery energy-storage system (BESS) hosted close to SR can provide short-term response while also acting as a critical backup power supply to the substation load during abnormal circumstances, such as a large industrial load shutting down, unanticipated change in renewable generation, or unplanned islanding of the microgrid. Wind plants are hosted at medium-voltage distribution levels whereas PV plants are hosted at low-voltage distribution levels. 


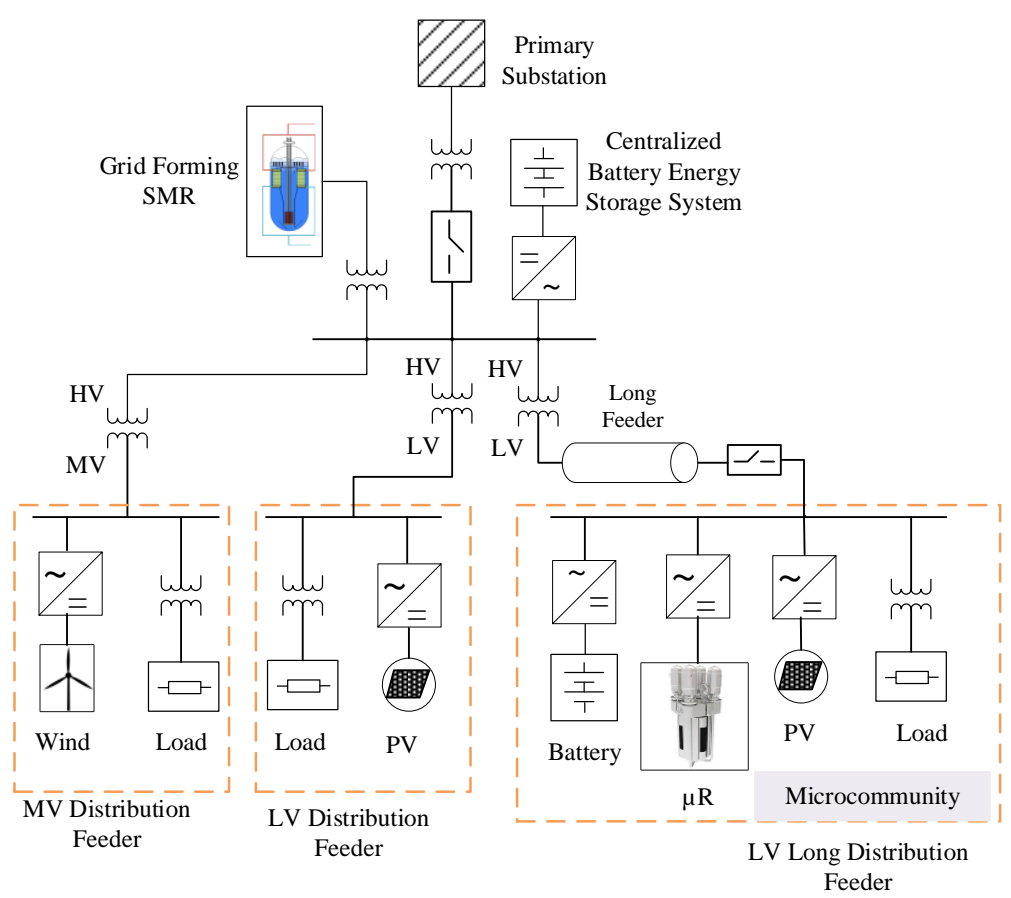

Figure 1.Using SRs with DERs in remote communities, which includes the option of more feeder-specific storage based on the cost and desired reliability/resilience.

These remote communities may include connections to long, weak distribution feeders that provide electricity to very small load centers located far from community substations. These remote feeders need reliable local generation closer to the load centers. Microreactors can be hosted alongside PV generation at remote ends of such low-voltage, long distribution feeders. As shown in Figure 1, a small microgrid could be constructed at the remote end, with a microreactor, BESS, and PV generation to reduce reliance on the power supply from the distant primary substation. The microreactor could provide baseload generation and load following, and the BESS could provide short-term response. Using this flexibility, a certain amount of PV generation could be hosted at the remote end as well. The microgrid could be designed with a direct-current (DC) power distribution system instead of an alternating-current (AC) power distribution system. Planners could consider the possibility of additional microreactors that, presumably under this scenario, might not be justified given the reliability of the shorter feeders.

In Figure 1, the breaker to the primary substation, when closed, represents the grid-connected mode. Open, it represents the islanded microgrid. Microgrids with an existing connection to a utility grid have flexibility in sizing SR plants unconstrained by local demand. The excess power can be sold to the utility grid, which is a potential revenue source, enhancing the return on investment for SR microgrids. Similarly, it may not always be possible to modulate generation units to fit the load demand of the microgrid. Having supplementary power from the utility grid allows cost reduction or at least deferral of one additional unit. The utility grid can provide flexible operation in such a system while the local generation assets can operate at the most-economic power levels. The requirement and size of energy storage will be reduced, limiting use only for critical conditions such as loss of grid connection. Microgrids with sufficient generating capacity also have the option to operate in islanded mode.

Microgrids without a transmission link to utility grids are required to produce power locally to meet local demand. The generation assets should be sized based on that local demand. Flexible power for load following and frequency control should come from assets within the microgrid. Energy storage will have a significant role to play for flexible operations in islanded microgrids. 
Most remote communities lack clean resources to fulfill their heating needs. SRs can offer cogeneration to fulfill both heat and electricity demands of remote communities [13][14]. This cogenerating configuration can boost the economic performance of the system while also offering means to flexible operation [15][16]. Figure 2 shows the configuration of an integrated electrical-heating network in a remote community. An SR in a primary substation can provide heat to consumers located nearby. Similarly, the microreactor located at the remote end of the feeder could provide for the heating needs of the local community.

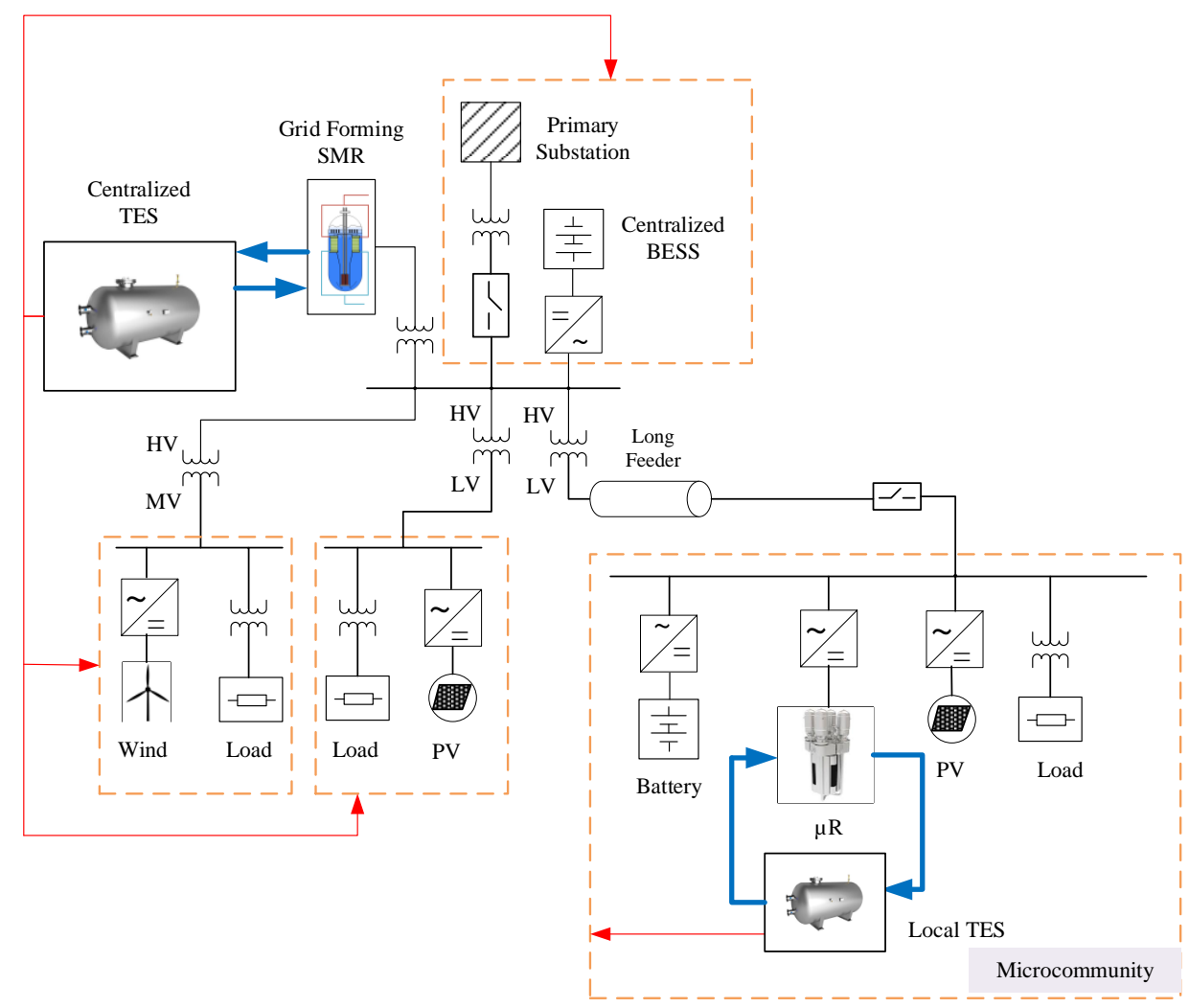

Figure 2. Integrated heat-electricity network in remote communities.

Modeling for community microgrids with SRs will be expanded beyond remote microgrids as part of the SR microgrid project-for example, to community microgrids and carbon-free communities. See Section 5.

\subsection{Virtual Power Plants}

Electrical power is traditionally transferred from producers to consumers on long transmission lines. Adding new generation capacity to meet growing load demand is a continuous process that today is increasingly done through distributed generation on local distribution networks. It is important to have the network capability adequately designed to meet demand. While energy demand and supply have grown steadily over the years, transmission capabilities have not been upgraded concomitantly [17].

Furthermore, increasing generation and demand-side intermittencies due to renewables and fast-changing load profiles have resulted in the uneven use of transmission capabilities. High peak utilization, but low average loading of the transmission networks means that it will not always be economical to upgrade transmission networks. Further, power transfer during peak hours results in very high transmission losses. The increased cost of transmission infrastructure has forced many utilities to consider dynamic pricing based on the intermittent behavior of demand and generation. One example of this is locational marginal 
pricing [18][19]. Due to high consumption at different times of the day, many utilities in large cities have opted to use dynamic pricing to recuperate the costs of additional power transmission [20].

Means to alleviate the issues in the transmission system, especially transmission congestion, are to tackle the issue locally at the problematic transmission node. Several studies explored the use of energy storage, such as grid-scale batteries, compressed-air systems, and flywheels, to alleviate transmission congestion [17][21]. However, all of these technologies have their costs and benefit tradeoffs. Finding an energy-storage technology that can provide the required power and energy capacity is one of those issues.

It is always prudent to analyze the possibility of adding a new generation in systems facing difficulties in power import due to transmission-congestion issues. The first hurdle is to find the right generation technology suitable for the specific locations. SRs are smaller in size and power level. They take small a plant footprint and could be transported using trucks. For these reasons, they can be hosted at any location in an electrical grid where power and ancillary service are needed. Wind and PVs could also be hosted, ideally at all locations, but their low average capacity factor in combination with the uncertainty and intermittency means wind and PVs alone are not reliable for providing transmission solutions. Targeting the problematic transmission nodes in an electrical grid with high locational marginal pricing, virtual power plants (VPPs) with a hybrid mix of generation technologies such as SRs, wind, and PVs could be constructed to provide power and ancillary services and to reduce the cost to consumers.

Figure 3 shows the configuration of a VPP constructed with the hybrid generation mix of SRs, wind, PVs, and BESS. The VPP is hosted near a transmission node where locational marginal pricing is very high. In addition to providing congestion relief, these VPPs can also provide ancillary services, such as reactive power support, frequency regulation, secondary- and tertiary-frequency control, and load following. VPPs continuously follow energy markets and look for opportunities to participate. Reducing the cost of electricity at or near a VPP is the priority of the proposed SR application for VPPs.

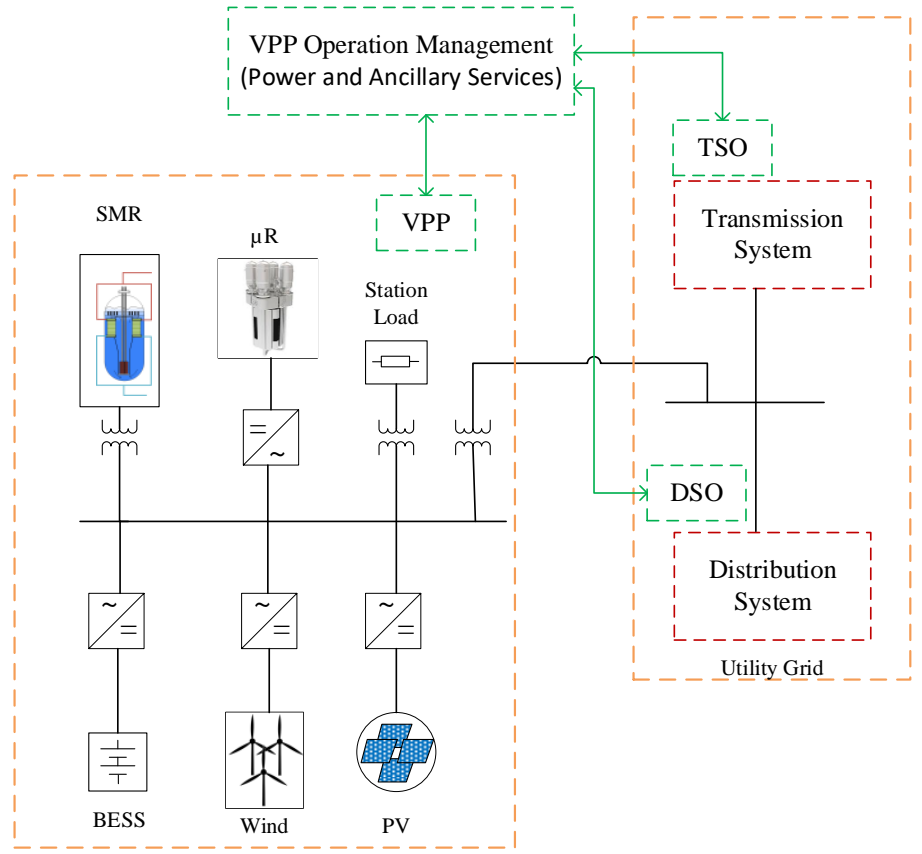

Figure 3. SR-based microgrid in VPP applications.

\subsection{Electric Vehicle-Charging Plazas}

GHG emissions in the transportation sector come from the burning of fossil fuels for road, rail, air, and marine transportation [22]. The transportation sector generates the largest portion of GHGs, 
contributing $29 \%$ of the total in the U.S., $82 \%$ of which comes from light-duty vehicles and heavy-duty trucks.

Mostly available as light-duty vehicles, electric vehicles (EVs) are widely accepted means to reduce carbon emission in the transportation sector. Currently, EVs customarily drive less than 200 miles on a full charge while there are a few (e.g., some models of Tesla) which can drive more than 300 miles. Regardless, charging stations are needed for EVs traveling longer distances. It is important that the electricity used for vehicle charging come from clean-energy resources. It is not always feasible to extend power lines to charging stations on highways or remote roads. Charging stations located far from a utility supply must have local generation systems. Load demand from EV charging stations correlates with the number of charging slots, the traffic at the plaza, and the distance to and from other charging stations or a nearby city. Some of the options for charging slots include DC Level 1 (a maximum of $80 \mathrm{~kW}$ at 50 $1000 \mathrm{~V})$, DC Level $2(400 \mathrm{~kW}$ at 50-1000 V), Tesla superchargers $(250 \mathrm{~kW}$ at $480 \mathrm{~V})$, and combined charging system DC fast charging (theoretical max of 4.5 MW at 200-1500 V). Auxiliary loads in the charging station can be both DC and AC [23][24][25].

EV charging stations differ from other microgrid use cases in the following respects:

- Because most loads on charging stations are DC, it is probably more sensible to have a DC generation and supply system, especially when SRs with DC output can be used.

- It is easier to limit the maximum load in EV charging stations. Therefore, it is easier to plan generation assets needed for the charging station.

- Because the generation and loads are located near one another, transmission issues are minimized, and issues of power quality and supply reliability are more easily addressed.

Charging stations may face large and intermittent step changes in loads on a regular basis. Similarly, they may go through periods without any loads. Finding the right mix of generation (SR, PVs, and BESS) is crucial here. Similarly, the system should be tested for its resilience against possible large disturbances.

Figure 4 shows a microgrid configuration proposed for an EV charging station. The proposed microgrid consists of microreactors as the primary generation system, along with PVs and a BESS. Because all generation facilities are located nearby, the power outputs could be controlled and coordinated. This points towards a DC microgrid. An AC grid supply is extended (if possible) to the proposed microgrid and connected via an inverter. The microreactor facility could consist of two or more modules - each 100-500 kW-depending on the demand at the charging station. Having multiple modules improves the reliability of the charging station and ensures the availability of power (redundancy) during an extended outage of one of the modules for refueling or maintenance. A PV plant could be hosted nearby to supplement the generation from microreactors. Wind turbines could also be hosted if the location and size of the system allow it. BESS is sized to provide power storage during intermittent load fluctuation and to capture intermittent power produced by PVs. BESS can also provide emergency power to microreactors during unexpected events. 


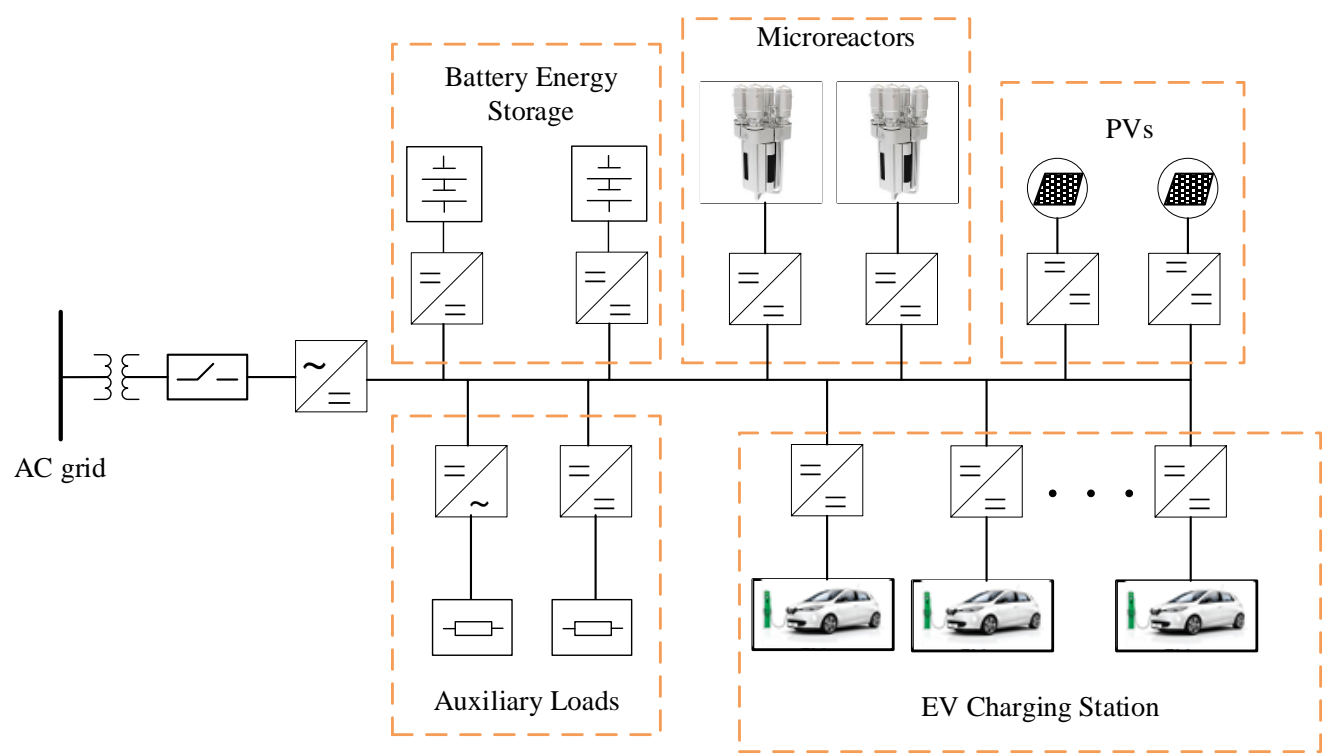

Figure 4. SRs in a microgrid with PVs for an EV charging station.

Hydrogen vehicles (HVs), available in both light-duty and heavy-duty transportation, are another means to reduce emissions in the transportation sector. Although less efficient than EVs, HVs range longer distances due to densely packed fuels. The EV microgrid shown in Figure 4 could also be upgraded to include a hydrogen fueling station, as shown in Figure 5. The heat produced by microreactors could be used for high-temperature electrolysis (HTE) to produce hydrogen on-site [26][27]. The process uses electricity to break down water molecules into hydrogen and oxygen gases. Using high-temperature steam for the HTE process significantly improves the efficiency and reduces the electrical power needed [28][29]. In fact, at $2500^{\circ} \mathrm{C}$, electrical input is unnecessary because water breaks down to hydrogen and oxygen through thermolysis. These temperatures are impractical; the HTE systems operate at between 100 and $850^{\circ} \mathrm{C}$. Considering the amount of heat energy necessary to produce one kilogram of hydrogen (141.86 megajoules both for heat and electricity), the efficiency is significantly higher for hightemperature steam [29]. At $100^{\circ} \mathrm{C}, 350$ megajoules of thermal energy are required (a $41 \%$ efficiency). At $850^{\circ} \mathrm{C}, 225$ megajoules are required (a $64 \%$ efficiency). If the steam temperature is lower, electrical heating, heat recuperation, or chemical heating could provide topping heat and boost the temperature.

The frequent ramping of a reactor is not economically and technically desirable. An EV charging station has frequent large step-demand variations and intermittent periods of light load. The operation of HTE could be coordinated at light-load periods, and the produced hydrogen gas could be stored on-site. Therefore, under the proposed integration of a hydrogen facility, the reactor could be continuously operated at its most-economical power level without the need for frequent ramping to follow demand on the electrical side. 


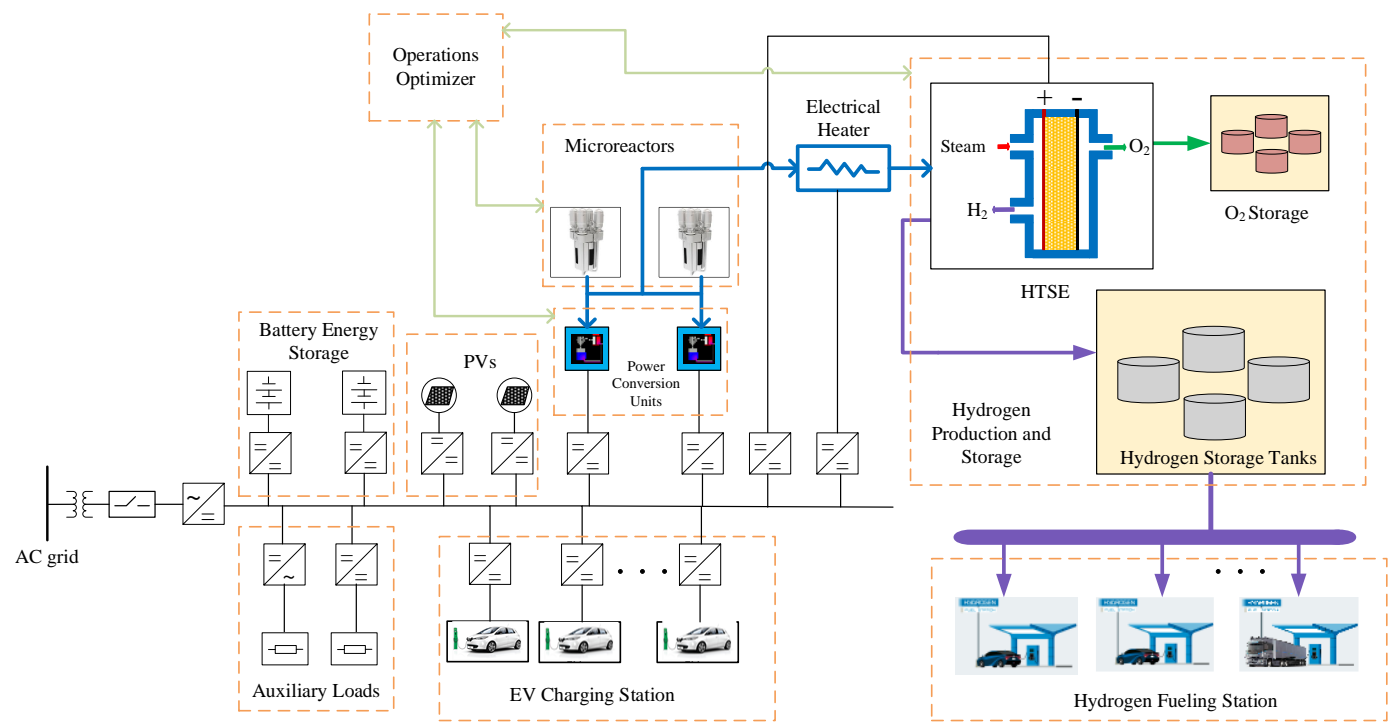

Figure 5. An HV fueling station added to the EV charging station for an integrated EV/HV charging plaza.

\subsection{Military Bases}

Military bases with secure boundaries and 24/7 mission-critical loads are prime locations for the initial installation of SRs [30]. The physical- and cybersecurity risks are mitigated by a controllable operating environment. Further, the high priority for energy security for national defense is a justification for the relatively high initial costs of installation and operation of first-of-a-kind nuclear technology. A distinguishing feature of military microgrids is mission-critical facilities, especially those related to command and control. Loads of secondary and lower importance can be rationed and used as flexibility for the stability of the microgrids when islanded. In bases that are adjacent to communities, interdependencies with critical facilities such as wastewater, transportation, and communications that support base operations and off-base personnel are important considerations as well.

The priority of these microgrids is to provide clean, reliable and economical power to critical infrastructure at military bases. Figure 6 shows a set of microreactors providing baseload generation for the facility. Wind, PVs, and BESS could also be hosted to support the microreactors. The microgrid might be connected to the utility grid, or it may be a completely isolated system. The critical loads may include electrical systems related to housing, life safety and health, public safety, communications, environmental systems, and critical mission support [31][32]. The controllable loads include less-important electrical systems that could be compromised in emergencies.

Military bases may also have transmission links with nearby renewable plants, community load centers, and remote communal facilities, as shown in Figure 6. The connection to wind and PV farms improves the reliability of the power supply at the base. Similarly, the military base can provide a powerevacuation route to these renewable facilities when the grid connection is unavailable. Also, the military base can provide power to the remote community whenever needed. 


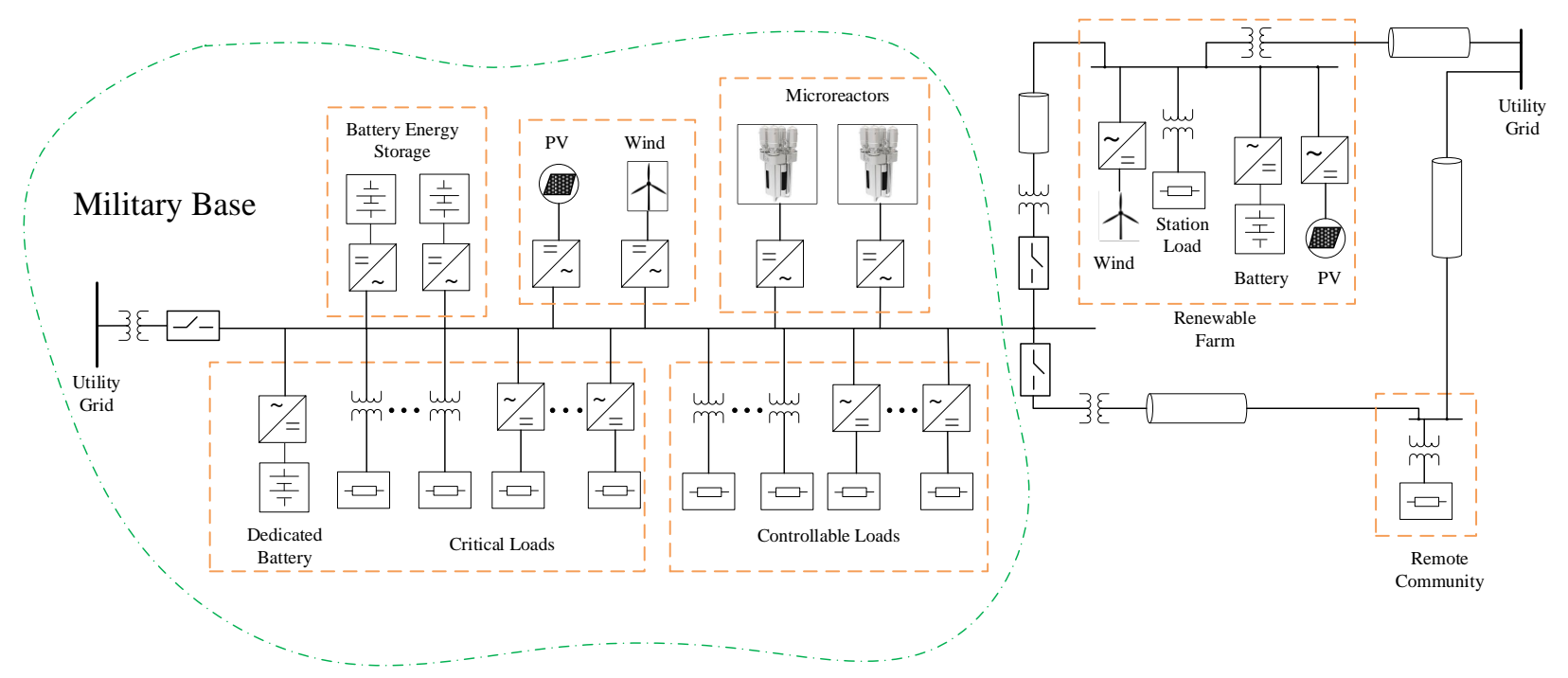

Figure 6. SR-based microgrid for a military base. The military microgrid may host local DERs and also connect with nearby renewables farms and isolated communities.

\subsection{Commercial Application-Airports}

Uninterrupted power is critical to airports to ensure safe air transportation. Grid-side failures can cause airports to face hours of outages and significant losses in revenue [33]. In order to reduce the impact of grid outages, airports adopt (mostly diesel) emergency generators as contingency backups. Recently, many airport facilities have developed local microgrids to enhance the reliability and resilience of the power supply. Microgrids developed at Pittsburgh International Airport, Pennsylvania, and Redwood Coast Airport Microgrid, California, are some examples [34][35][36]. Pittsburg microgrid includes a gas-fired generator and PVs whereas the Redwood Coast microgrid is a 100\%-renewable community-scale microgrid with PVs and BESS [34]. In both examples, SRs could be an excellent addition for either replacing gas-fired generators or improving the reliability and resilience of allrenewable microgrids.

Figure 7 shows the configuration of an SR-based microgrid for airport facilities. Airports need a large power supply to conduct various critical functions, including air communication, traffic control, ground surveillance, radio communication, and ground-light controls [37][38]. The air-traffic control system continuously monitors airport situations and guides aircraft with ground navigation advice to ensure secure and safe mobility in and around the airspace of the airport. Air-route surveillance radar, airport surveillance radar, and secondary surveillance radar are some of the subsystems under the air-traffic control system that need an uninterrupted power supply. The air-communication system is used by airline companies to identify an aircraft's position and to ensure secure navigation. The radio facility helps aircraft to identify their positions and helps the safe landing of aircraft. Ground lighting is also critical for the safe landing of aircraft at airports. The meteorology facility is present in airports to identify, predict, record, and inform about weather situations to enable the safe operation of aircraft. Other electrical loads in airports include air-conditioning, water, and sewage facilities. 


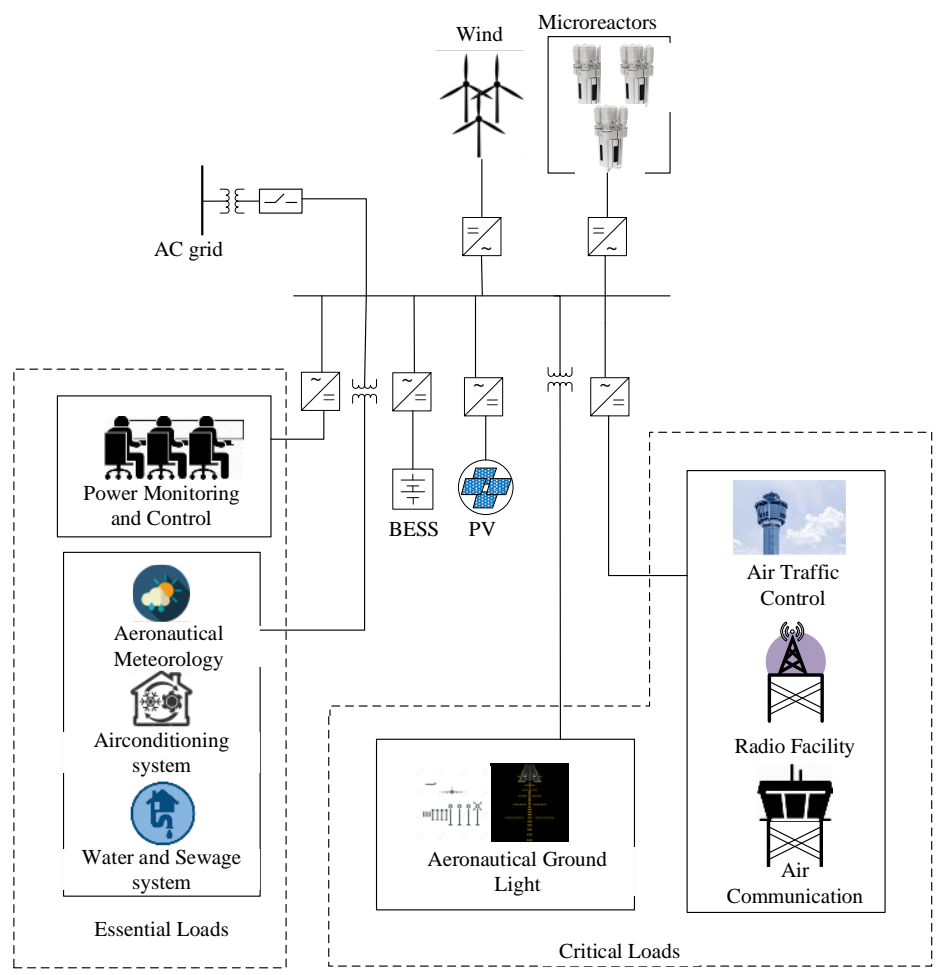

Figure 7. SR-based microgrid for commercial application in airports.

Local generation should meet airport demand, even when the grid connection is lost. Generation planning to ensure uninterrupted power supply to critical loads in these microgrids is a major consideration in the process for cost-effective design. Not shown in the above configuration, each critical facility can have a dedicated BESS. The power-control and operation center should be capable of detecting and dealing with cyberattacks. Microgrid should meet minimum resilience and reliability standards and operate seamlessly during severe circumstances like grid loss, adverse weather, and cyberattacks.

\subsection{Space Application}

This use case includes future microgrids for a space station, lunar facility, or Mars station. Unlike microgrids on Earth, space stations are not connected to utility grids. Therefore, the generation resources must be in loco to fulfill the demand during normal and abnormal situations [39]. Space stations have a series of critical loads that cannot be compromised under any circumstances. Generation assets should be planned in order to meet the demand at multiple redundancy levels. In addition to meeting load demand, maintaining the quality of power supply within highly confined areas, avoiding any critical transients in the system, and continuous observation and prediction of system status are essential requirements. Electrical units should be in constant communication with each other through failsafe management systems.

Critical loads include nutrition (plantation, stock), water management (recycling, stock), oxygen (supply, storage), space (sleep, toilet, storage room), infirmary, electronic equipment (computers, robots, stable connection to the Earth), and exploration equipment (rovers, drills, transportation) [40]. The International Space Station (ISS) currently uses solar PVs to harness power from sunlight. The installed $\mathrm{PV}$ arrays can generate about $240 \mathrm{~kW}$ from direct sunlight and between 84 and $120 \mathrm{~kW}$ average power (cycling between sunlight and shade) [40][41]. Because the PV arrays face direct sunlight, they can generate power with more efficiency than PVs on Earth. The ISS currently hosts seven crewmembers. 
Because the facilities on the Moon or Mars are located farther from the Earth, they need more power than ISS does, fixated in Earth's orbit. Exploration and habitation on those surfaces increase the energy demand. Stations on the Moon or Mars may not be able to harness solar power as effectively as at the ISS. In the case of the Moon, sunlight will not be available for 15 continuous days. Assuming that the base is located on the Earth-facing side of the moon, the solar collection is zero from half-moon to new moon and through to the next half-moon phase. In the case of Mars, located farther from the Sun than the Earth,

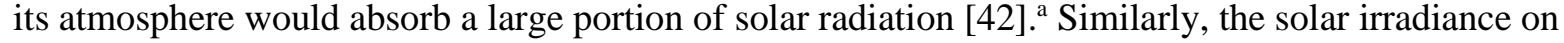
Mars is as intermittent as on Earth. This underscores a definite need for exceptionally high reliability for power generation at extraterrestrial land stations.

Figure 8 shows a microgrid system for space applications that could host a single or multiple microreactors, based on energy needs. Solar PVs and BESSs are hosted along with microreactor units. The station-management system is designed for continuous monitoring, predicting, and controlling generation and loads to reduce uncertainty in the system. The power system is designed to provide both AC and DC outputs to critical and non-critical loads. The power distribution voltage could be between $120-240 \mathrm{~V}$ (AC and DC - for ISS it is $120 \mathrm{~V}$ ). For planetary stations, there may be a need to consider distribution at higher DC voltages because low voltages mean higher current, and greater mass in the conductors may need to be minimized due to the increased expense to mission mass budgets (more weight means higher costs, more flights, etc.). Because continuity of power supply is essential for the lifefunctions in space facilities, the resilience of microgrid to ride through the worst eventualities and to provide uninterrupted power to critical units is the main priority of the proposed microgrid.

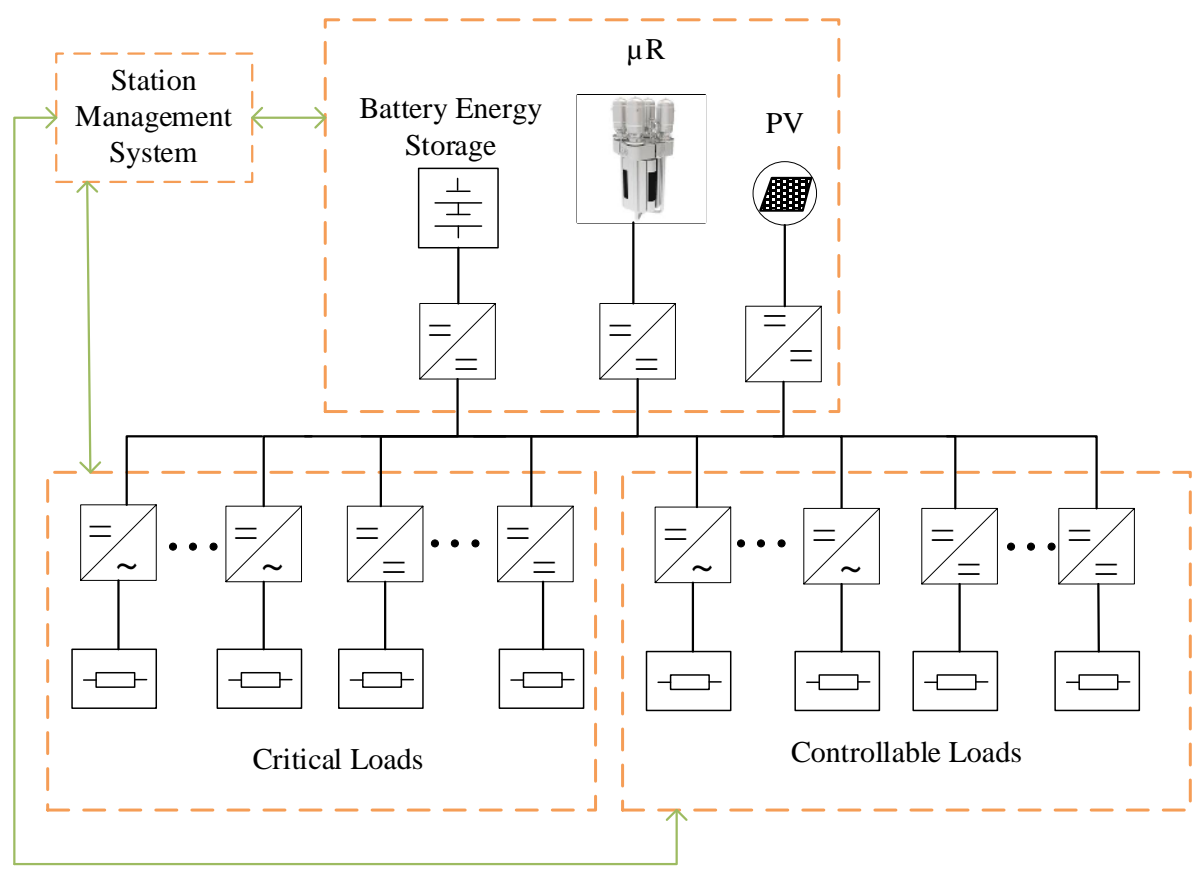

Figure 8. An SR-based microgrid for space application where the critical loads are life-safety functions; on an inhabited station, most loads are mission-critical, but there may be some non-life-safety or missionconfigurable loads that would be flexible.

a The Martian surface is $586.2 \mathrm{w} / \mathrm{m}^{2}$, compared to $1361 \mathrm{w} / \mathrm{m}^{2}$ on Earth's surface. 


\section{REQUIRED FEASIBILITY STUDIES}

This section discusses studies relevant to various microgrid use cases described in the previous section to provide assessment frameworks to evaluate microgrid feasibility in the planning and operation stages. The summary discusses several studies, some of which may be essential to certain microgrid use cases while not a priority for other applications.

\subsection{Siting}

Finding a site is an important step before nuclear power plant (NPP) deployment. The availability of electric-grid connection, surface and subsurface geology of the plant's foundation, geography of the plant location - including population density and economic activities - availability of cooling water, and environmental and legal aspects are some of the considerations that must be analyzed before finalizing a site [43]. Reactor technologies with water cooling need to have proper access to the required volume of cooling water. Usually, NPPs are required to have a certain exclusion area surrounding the reactor to avoid any compromise to safety and or hazard to the general population [44][45][46].

Unlike conventional NPPs, one of the major design considerations of SRs is flexibility in their siting. Some recent innovations - inherent or passive safety features, less or no requirement for cooling water, smaller size and power ratings, and modularity - have significantly broadened the potential siting locations for their deployment. The exclusion area for SRs may be reduced; some vendors argue that it may shrink to within the plant boundary. Nevertheless, some range of exclusion might be needed based on nuclear-regulatory requirements [45]. Due to limited siting options, SRs in microgrids should be designed and planned to address these highly sensitive issues for safety under emergencies and publicacceptance reasons. For terrestrial-microgrid use cases, SRs should be collocated within the microgrid boundary or a few miles of the microgrid center. In the case of space applications, SRs are hosted inside the station. For VPPs, ideal sites will be the ones that offer advantages for aggregation with renewable generation and storage and connections at locations favorable for participation in markets and assisting in relieving reliability or security issues such as transmission congestion.

\subsection{Generation Planning}

Generation assets within a microgrid should be sized sufficiently to meet the demand within its boundaries and any surplus capacity for export of power to the grid (and markets), commonly called "oversizing," for financial benefits. The mix of SRs, energy storage, intermittent renewables, and flexible loads must be assessed properly in the early stages of the design process. Also, generation planning considers operational constraints, the uncertainty of renewable generation, and load demand, along with the probabilities of generation and supply contingencies.

In remote and off-grid communities, the generation capacity should match local demand whereas the communities with transmission links to the utility grid have more flexibility for scaling generation capacity near local demand. Remote communities with sparse loads may need to plan or distribute generation capacity at remote ends (as shown in Figure 1) in addition to the centralized capacity planned at the substation level. To meet load demand at remote ends, small-sized microreactors, PVs, and BESS could be hosted to develop sustainable microcommunities within a larger remote community. At the microcommunity level, the load variation would be more significant than it is at the substation level. Short-term disturbances are amplified, and the size of the BESS would be at a larger ratio to the size of the microcommunity.

In the case of VPPs, generation assets could be sized to the needs of the grid. A VPP can be hosted at the most-economical size, which could range from a fraction of the load of the target distribution system to several times its size. Considering the investment necessary for VPPs, it might be sensible to maximize the generation output from VPPs, which includes strategies to keep reactor power levels close to the extremes, with a minimal number of reactor maneuvers, and extracting maximum power from wind and 
PVs. Continuous coordination with distribution system operator (DSO) and transmission system operator (TSO) facilities is important to optimize generation in the system. With pricing and congestion information received from the TSO and load demands received from the DSO, the VPP evaluates reactoroperation schedules and updates them on daily basis. When the power from the TSO is high priced, the VPP covers the load of the DSO or at least a fraction to reduce it to the most-economical level. Further, the VPP could be sized to enable it to supply the transmission side, if necessary and economical. All of these evaluations are also necessary when sizing generation assets.

In charging plazas, the power-distribution system could be DC, as shown in Figure 4. The voltage levels would be selected based on the voltage levels of charging slots. The charging microgrid plazas are characterized by high peak demand and low load factors. Generation assets may be sized by looking at average demand in addition to peak demand. For example, the SRs might be considerably smaller compared to peak demand, and a BESS would supplement the power capacity to fulfill the demand during system peak. Because the system faces large demand variations and regular intervals of light-load periods, the BESS should be sized with large power and energy ratings. Similarly, when demand variation is already large, renewable generation in the system needs to be minimized. In integrated HV/EV charging plazas, the presence of storage facilities on the hydrogen side provides additional flexibility for reactor units to operate at close to their rated power levels at all times. The generation assets (SRs, PVs, wind), storage components (BESS and $\mathrm{H}_{2}$ storage tank), and loading stations (charging slots and $\mathrm{H}_{2}$ refueling stations) should be designed to meet the potential traffic while also maximizing the utilization factor.

In military bases, generation capacities would be sized to meet the demand of the facilities and to provide power to nearby off-grid communities or communal facilities. In addition, a certain level of generation redundancy is necessary to ensure an uninterrupted power supply to the critical infrastructure of the military base.

In space applications, the priority would be reliability and resiliency. Continuity of power supply with critical loads is vital. Further, microgrids should also occupy as little space as possible. The capacity of the generation assets needs to fulfill the load demand while meeting the redundancy level required for the critical systems. Space microgrids must be designed with a very high degree of redundancy, capable of meeting system demands and minimum performance levels at multiple simultaneous contingencies.

\subsection{Operational Framework and Feasibility}

Microgrids with nuclear power assets should have an operational framework designed with clearly defined protocols for normal and abnormal scenarios to avoid any uncertainty in decision-making during reactor operations. Microgrid control governs all flexible operational assets to meet both short- and longterm power-flexibility requirements. The flexibility requirements of microgrids increase with the level of intermittent renewable-power assets. It is important to understand the operational limits of microgrid assets. Typically, reactor maneuvering has restrictions in terms of ramp rates, total change, and power cycles per day specified by the reactor design basis [47][48][49]. Reactor power control needs extra precautions because it has an associated safety factor. BESS can bridge the mix of SRs and renewables, providing additional flexibility for the system. BESS can provide both unplanned quick load-following response and frequency control with SRs limited to planned variations over a longer duration [50]. For abnormally large short-term disturbances, steam bypass could be used wherever applicable. If other heat applications are integrated, planned steam distribution with thermal-energy storage on the heating side can support load-following response [15][16].

Evaluations of operational feasibility for a microgrid configuration involve static and dynamic simulations that consider various normal and abnormal operating circumstances (e.g., faults, contingencies). A detailed, dynamic model of the system is necessary to accurately assess system response under normal and abnormal operations. In such simulations, wind and PV plant models should reflect their generation intermittency and uncertainty. The system should meet standard static and dynamic performance during normal operations. Under abnormal operations, the system should be able to 
meet minimum normalcy with acceptable risk, which also depends on the severity of abnormalities. A probabilistic assessment is necessary to quantify operational risk. DERs such as wind, PVs and BESS may need to be resized to meet the operational performance of the system. While the system should be able to operate without grid support, coordination with the grid during normal and abnormal situations should be analyzed. Microgrids with grid connections should have clear protocols for operation in both isolated and grid-connected modes and a seamless transition from one mode to another.

In VPPs, operational decisions are based on the power and ancillary service requested by the grid market. The power-dispatch schedule from the VPP to the grid connection is generally decided on a dayahead basis. The rest of the supports are part of ancillary services. The planned and unplanned loadfollowing services are provided based on predefined setpoint levels whereas frequency control is automatic, with pre-agreed droop settings. Apart from services to the grid, the VPP should also coordinate power outputs of generation assets to meet grid needs. Services provided by VPP to the grid are sometimes prescheduled and sometimes provided in real-time. In EV charging plazas, microgrid loads often face large and frequent step changes. It is essential to evaluate the system response and dynamics under such operating conditions. The static and dynamic performance of the system under these unique operating conditions must be properly assessed. While SRs may need to be more flexible to meet increased power-variation requirements, the power rating of the BESS should be sized to enable capture of excess generation during light-load periods. Both event-specific and operational simulations are necessary to ensure the feasibility of SRs in variable conditions. The probabilistic assessment with both operational and response risk (modified to include system dynamic performance) might be suitable for such systems. When integrated into an EV/HV charging plaza, the microgrid controller should include a protocol to distribute steam from the reactor for electricity generation and hydrogen production. The integrated energy system with storage components provides additional flexibility to the reactor units. The hydrogen could be produced during times of light load on the electrical side. The steam supplied to the electrolyzer can be regulated based on the electrical load to improve load following on the electrical side. This allows the microgrid to reduce the cost to the BESS.

Compared to terrestrial microgrids, it is even more important for space microgrids to consider all possible operational scenarios to reduce and possibly eliminate any uncertainty in decision-making. Because human life is at stake, the system should have well-defined protocols to operate in different emergency scenarios, quick recovery from each emergency state, quick decision making to transition between states and seamless activation of system redundancies during component failure.

\subsection{Economic Evaluation and Optimization}

In addition to operational feasibility, microgrid configurations should be economically viable. The first step of economic evaluation is to develop accurate cost models for SRs as the first of a kinds (FOAKs) have yet to be built and deployed. Economic optimization should include the uncertainty model of renewable generation and load in the microgrid. The operational scheme used for the system can have a significant impact on operational costs. For example, maintenance cost increases due to frequent flexible operation of SRs and inefficient fuel burnup at lower power levels are equally significant as the savings in fuel cost by reducing reactor power. Moreover, coordination and power exchange with the grid should be analyzed to improve the financial performance of the system. The need for a redundancy level can be incorporated into economic optimization with reliability metrics. The economic assessment may also include the role of microgrids in reducing carbon emissions. This optimization enables the reevaluation of the power and energy adequacy of the system to determine sizing and operation for the most-economical outcome. Economic analysis also looks at options beyond the system boundary if that leads to certain financial benefits to the project. For example, in remote communities with access to a utility grid, it might be economical to invest in reinforcing the long distribution line and defer the installation of microreactors at remote ends. Similarly, if an existing grid connection allows, excess electricity can be sold to the utility grid, which affects the economic scaling of generation capacity. 
In EV charging plazas, load demand has both large peak load and low load factor. It may not be economical to host renewables because this further increases the need for flexible power. The number of charging slots correlates to the peak demand of the microgrid. By reducing the number of charging slots (i.e., demand-side management), peak load shaving can be achieved to minimize the cost in generation assets at the expense of consumer-side delays. The sizing of a charging station should be optimized such that the investment is paid back in a reasonable time. Integrated EV/HV charging plazas have the potential for higher efficiency. The potential traffic of HVs and EVs at the station should be properly evaluated in the planning stage. The sizing of HTE units and hydrogen refueling stations should be based on the demand for economical operation. The distribution of steam for hydrogen and electricity should also be optimized to result in the most-economical output. Hydrogen fuels can be stored and supplied to remote consumers; this might help determine the economic sizing of SRs. In space microgrids, the redundancy level should be maintained at the expense of increased system cost, but the overall cost can be optimized while meeting the required operational and reliability constraints.

\subsection{Risk Analysis}

Risk analysis involves the identification of various operational and nonoperational contingencies that could impact the safety and integrity of the reactor system (and the stability and operation of the microgrid). Modern SRs are designed with passive safety features, allowing the safety components to function without external electrical power. This greatly reduces the probability of grid-centered or powerrelated core damage in SRs. These contribute the major portion of core damage in conventional NPPs, and their elimination avoids initiating events that could lead to the failure of the nuclear system. Probabilistic risk assessment is widely used to explore the sequence of events leading to such system failure.

In space applications, the probabilistic risk assessment could be used to rigorously study the events that may threaten the power supply of space stations or extraterrestrial facilities. Risks can be quantified as associated by matching probabilities with fault-tree/event-tree analyses for the factors leading to the failure of the power supply. Redundancies could be added to eliminate or reduce the probability and frequency of dominant events, to review the standards of probabilities applicable for the space bases, or, if needed, to build new standards. Detailed accident scenarios should be simulated to analyze the sequence of events in abnormal scenarios, the response of protective and preventive equipment, and the reliability of communication channels and human interaction that can prevent, control, mitigate or worsen such circumstances. 


\section{Technoeconomic Model and Cost Analysis of Small Reactors}

The technoeconomic model is necessary to examine the cost competitiveness of SRs compared to other forms of generation technology. The development of a XENDEE-based technoeconomic model is planned with the following datapoints:

- Investment costs $(\$ / \mathrm{kW})$

- Installation costs $(\$ / \mathrm{kW})$

- Installation size/unit size $(\mathrm{kW})$

- Operations and maintenance (O\&M) costs (in $\$ / \mathrm{kWh}$ and/or $\$ /$ year)

- Electric efficiency (in percent of fuel input)

- Heat-to-power ratio (kWt of heat per $\mathrm{kW}$ of electricity generated)

- Lifetime (years)

- $\quad$ Minimum loading $(\%)$

- Minimum up and down times in hours

- Decommissioning costs $(\$ / \mathrm{kW})$

- Waste-handling costs of old fuel.

Due to limited empirical data on the proposed size of SRs, the above-mentioned datapoints are difficult to estimate. Annex A provides a detailed literature study focused on the cost and technical capabilities of conventional NPPs and some SR projects that are in an advanced stage of development, where data can be derived. Calling upon the information in Annex A, this chapter discusses the datapoints and estimates of data that are available for technoeconomic modeling of SRs in microgrids.

\subsection{Definition of Terms}

The industry is in the early stages of modeling SRs in microgrids (and any other applications that are integrated with other resources and loads) and their deployment and interactive management with energymanagement systems, whether microgrid controllers or utility advanced distribution-management systems. In developing datapoints and data inputs for these models, it is useful to define the terms specifically with reference to the unique aspects of SRs. The table below gives definitions that apply to SRs in microgrids.

Table 1. Definition of the terms used in technoeconomic modeling.

\begin{tabular}{|l|l|}
\hline Terminology & Description \\
\hline All-in capital costs & $\begin{array}{l}\text { Sum of overnight construction cost, escalation cost and interest during } \\
\text { construction (IDC). }\end{array}$ \\
\hline $\begin{array}{l}\text { Overnight costs } \\
\text { (OCs) }\end{array}$ & $\begin{array}{l}\text { Overnight capital costs include the engineering, procurement, and construction } \\
\text { cost (including contingency) and the owner's costs, exclusive of escalation and } \\
\text { interest. The OC refers to the cost of the plant if it could be constructed } \\
\text { overnight. }\end{array}$ \\
\hline
\end{tabular}




\begin{tabular}{|c|c|}
\hline Terminology & Description \\
\hline Owner's costs & $\begin{array}{l}\text { This category includes owner's agent/engineer costs; licensing and project- } \\
\text { development costs, project management and oversight; owner's contingency; } \\
\text { administration building and security; site facility-transportation upgrades and } \\
\text { site improvements; interconnects and switchyard upgrades; spare parts; the } \\
\text { initial nuclear fuel core; banking and legal fees for state permitting; property } \\
\text { tax; sales tax; and working capital. Owner's costs also include site-specific } \\
\text { development costs, such as transmission costs, which can vary widely from } \\
\text { site to site. }\end{array}$ \\
\hline $\begin{array}{l}\text { Detailed design and } \\
\text { engineering cost }\end{array}$ & $\begin{array}{l}\text { Cost of the detailed engineering of equipment and plant facilities needed to } \\
\text { bring a design to completion in order to support construction. These costs } \\
\text { include completion of the detailed design, the preparation of construction } \\
\text { drawings, the specification of system components, procurement engineering } \\
\text { including the preparation of bid packages for suppliers, a general site layout } \\
\text { (that would then be adapted to individual plants), and all nonrecurring design } \\
\text { and engineering work at the manufacturing site. }\end{array}$ \\
\hline $\begin{array}{l}\text { Engineering, } \\
\text { procurement, and } \\
\text { construction (EPC) } \\
\text { costs }\end{array}$ & $\begin{array}{l}\text { These include direct costs for the nuclear steam-supply system, the turbine } \\
\text { generator, and the balance of the plant, as well as indirect costs such as } \\
\text { engineering and construction services. EPC costs also include an allowance for } \\
\text { contingencies and an allowance for escalation. EPC costs include FOAK } \\
\text { engineering costs. }\end{array}$ \\
\hline $\begin{array}{l}\text { Decontamination } \\
\text { and } \\
\text { decommissioning } \\
\text { costs }\end{array}$ & $\begin{array}{l}\text { Cost of demolition and clearing of the NPP after the completion of its } \\
\text { operating life. }\end{array}$ \\
\hline $\begin{array}{l}\text { First-of-a-kind } \\
\text { engineering } \\
\text { (FOAKE) costs }\end{array}$ & $\begin{array}{l}\text { These costs are associated with the upfront design and engineering design } \\
\text { work required to obtain design certification and a combined construction and } \\
\text { operation license from the Nuclear Regulatory Commission (NRC). }\end{array}$ \\
\hline $\begin{array}{l}\text { Levelized cost of } \\
\text { electricity }(\mathrm{LCOE}) \text { : }\end{array}$ & $\begin{array}{l}\text { This cost includes the OC and total financing costs, as well as the costs of } \\
\text { operation, fuel, and maintenance and is expressed in dollars per MWh and } \\
\text { cents per kWh. }\end{array}$ \\
\hline $\begin{array}{l}\text { Nth-of-a-kind } \\
\text { (NOAK) plant }\end{array}$ & $\begin{array}{l}\text { The estimated costs for these plants do not include major design costs and } \\
\text { assume that lessons learned have been incorporated in this build generation; } \\
\text { thus, the learning curve has been surmounted. }\end{array}$ \\
\hline
\end{tabular}

\subsection{Technoeconomic Model}

SRs are sized based on the requirements of microgrid applications highlighted in this report. The characteristics of SRs are still part of the discussion, but their technoeconomic models were developed considering information from past NPPs, design data from vendors, and some sensible deductions from a generalized understanding of the technologies. The proposed cost models are for SR plants with a single reactor unit. The economic benefit of co-siting multiple SR modules in a microgrid is not analyzed in this report. The modeling of multi-module SRs for larger microgrids may follow in future work. Ten different parameters are selected to populate the proposed technoeconomic models in accordance with XENDEE modeling requirements. The detailed calculations are discussed below.

\subsubsection{Investment Cost}

The total investment cost is the sum of OC, initial fuel-loading cost, and the cost of financing (IDC). 


\subsubsection{Overnight cost}

The first SR has yet to be fully tested and is not ready for field deployment. SRs propose a significant shift in the approach to deployment from traditional large reactors. For this reason, cost models of SRs are still uncertain. In the literature study section, we discussed cost-estimation approaches currently being used for NPPs. In the first approach, the Code of Account (COA) sheets are populated, which requires detailed values for different cost components [51]. While the COA method provides accurate cost estimates, the data for individual components are difficult to obtain or estimate accurately.

In the second approach, a fixed scaling factor is used to scale the OCs of large NPPs to obtain cost estimates for smaller plants. The scaling factor is calculated from the statistical fitting of the cost data for different NPPs in past. This scaling approach is intended for plants with similar technology, siting, and time considerations. Some of the studies used this approach for SRs as well [8][52]. For SRs, the OC was first reduced using a scaling factor, and further reduction was applied based on differences in design and deployment. While the approach will provide cost estimates with acceptable accuracy for large NPPs (i.e., 100-600 MW), the traditionally used economy-of-scale scaling factors to extrapolate the size dependence of reactor investment costs is not valid for SRs (single modules or larger than 20 total megawatts) and especially for microreactors for four main reasons:

1. The sizes are very small, significantly scaled down from large NPPs.

2. The land required (land usage, exclusion zone, low population zone) is significantly smaller due to inherent plant and radiation safety (possibly shrinking the exclusion zone to the plant area). The NuScale report [53] submitted to the NRC for licensing states that the exclusion zone of an SR plant is the plant boundary, and any place outside the plant can be inhabited.

3. The reactor modules and components, such as turbines and generators, are factory built. This significantly decreases the time and cost of production, quality control, installation, and commissioning.

4. The on-site construction time is expected to be significantly lower for SRs. This reduces pricing for contingencies compared to NPPs.

When SRs go to the factory-production stage, an important aspect to be considered in cost estimation is the modularity of the system and the acquisition of components that are already available on the market and in use. For large NPPs, the plant design that drives the reactor and plant structures are mostly custom made: one-offs at a high cost. Here, we propose a hybrid method combining COA and scaling-factor methods to tackle the cost-estimation problem. In this hybrid approach, scaling factors are given for individual cost components to obtain the total OC. Scaling factors are analyzed and perturbed until they give a sensible result for cost estimates.

Table 2 lists cost components for different sizes of large NPPs as a percentage of the total OC of a $300 \mathrm{MW}$ plant. The scaling factor in the last column of Table 2 is the factor " $n$ " fitted into Equation (2) for each cost component.

$\operatorname{Cost}\left(P_{A}\right)=\operatorname{Cost}\left(P_{B}\right) *\left(\frac{P_{A}}{P_{B}}\right)^{n}$

Table 2. Cost components in nuclear power plants (as a percentage of $300 \mathrm{MW}$ plant).

\begin{tabular}{|l|c|c|c|c|c|}
\hline \multicolumn{1}{|c|}{ Cost Component } & $\mathbf{3 0 0} \mathbf{~ M W}$ & $\mathbf{6 5 0} \mathbf{~ M W}$ & $\mathbf{1 0 0 0} \mathbf{~ M W}$ & $\mathbf{1 3 5 0} \mathbf{~ M W}$ & $\begin{array}{c}\text { Scaling } \\
\text { Factor }\end{array}$ \\
\hline Land, land rights, site utilities & 2.8 & 2.9 & 3 & 3.1 & 0.07 \\
\hline Buildings and structures & 14.8 & 21.6 & 26.7 & 31 & 0.49 \\
\hline Steam production and discharge processing & 23.5 & 39.4 & 53.5 & 66.8 & 0.69 \\
\hline Turbine and generators & 10.5 & 17.7 & 23.7 & 29.1 & 0.68 \\
\hline
\end{tabular}




\begin{tabular}{|l|c|c|c|c|c|}
\hline \multicolumn{1}{|c|}{ Cost Component } & $\mathbf{3 0 0} \mathbf{~ M W}$ & $\mathbf{6 5 0} \mathbf{~ M W}$ & $\mathbf{1 0 0 0} \mathbf{~ M W}$ & $\mathbf{1 3 5 0} \mathbf{~ M W}$ & $\begin{array}{c}\text { Scaling } \\
\text { Factor }\end{array}$ \\
\hline Control and instrumentation & 5.6 & 8.9 & 11.5 & 13.8 & 0.6 \\
\hline Miscellaneous plant equipment & 2.5 & 3.2 & 3.7 & 4.1 & 0.33 \\
\hline Water intake and discharge structures & 1.9 & 3.6 & 5 & 6.4 & 0.81 \\
\hline Engineering and design & 13.3 & 16.4 & 18.9 & 21.1 & 0.31 \\
\hline Construction services & 6.2 & 7.1 & 7.8 & 8.5 & 0.21 \\
\hline Indirect miscellaneous & 4 & 4.7 & 5.4 & 6 & 0.27 \\
\hline Contingencies & 2.7 & 4.1 & 5.2 & 6.2 & 0.55 \\
\hline Owner's cost & 12.3 & 15.4 & 17.5 & 19.1 & 0.29 \\
\hline Total OCs & $100 \%$ & $145 \%$ & $182 \%$ & $215 \%$ & 0.51 \\
\hline
\end{tabular}

Table 3 lists the costs of four reference plants in actual dollars instead of percentage. As a first step, the cost components are extrapolated based on the cost trajectory seen for the given four reference plants. We estimate the cost of SRs of sizes $100 \mathrm{~kW}$ to $20 \mathrm{MW}$. By simply fitting to the trajectory, Table 4 is obtained with the actual dollar cost for each component.

Table 3. Cost components in nuclear power plants (in millions of dollars).

\begin{tabular}{|l|l|l|l|l|}
\hline \multicolumn{1}{|c|}{ Cost Component (in millions of \$) } & 300 MW & 650 MW & 1000 MW & 1350 MW \\
\hline Land, land rights, site utilities & 41.93531 & 43.433 & 44.93069 & 46.428379 \\
\hline Buildings and structures & 221.6581 & 323.501 & 399.8831 & 464.28379 \\
\hline Steam production and discharge processing & 351.9571 & 590.0897 & 801.264 & 1000.4567 \\
\hline Turbine and generators & 157.2574 & 265.0911 & 354.9524 & 435.82769 \\
\hline Control and instrumentation & 83.87062 & 133.2944 & 172.2343 & 206.68117 \\
\hline Miscellaneous plant equipment & 37.44224 & 47.92607 & 55.41452 & 61.405276 \\
\hline Water intake and discharge structures & 28.4561 & 53.91683 & 74.88448 & 95.852138 \\
\hline Engineering and design & 199.1927 & 245.6211 & 283.0633 & 316.01252 \\
\hline Construction services & 92.85676 & 106.336 & 116.8198 & 127.30362 \\
\hline Indirect miscellaneous & 59.90759 & 70.39141 & 80.87524 & 89.861379 \\
\hline Contingencies & 40.43762 & 61.40528 & 77.87986 & 92.856759 \\
\hline Owner's cost & 184.2158 & 230.6442 & 262.0957 & 286.05872 \\
\hline Total OCs (in Millions \$) & 1499.187 & 2171.65 & 2724.297 & 3223.0281 \\
\hline
\end{tabular}

Table 4. Cost components of SRs (based on old scaling factors).

\begin{tabular}{|l|r|r|r|r|r|r|r|}
\hline Cost Components (in millions of \$) & \multicolumn{1}{|c|}{$\begin{array}{c}\text { MW } \\
\text { Land, land rights, site utilities }\end{array}$} & \multicolumn{1}{c|}{$\begin{array}{c}\text { MW } \\
\text { MW.25 }\end{array}$} & \multicolumn{1}{c|}{$\begin{array}{c}\text { MW } \\
\text { MW }\end{array}$} & $\begin{array}{c}\text { M } \\
\text { MW }\end{array}$ & $\begin{array}{c}\text { 5 } \\
\text { MW }\end{array}$ & $\begin{array}{c}\text { 10 } \\
\text { MW }\end{array}$ & $\begin{array}{c}\text { 20 } \\
\text { MW }\end{array}$ \\
\hline Buildings and structures & 4.34 & 6.80 & 9.56 & 13.44 & 29.64 & 41.66 & 58.56 \\
\hline $\begin{array}{l}\text { Steam production and discharge } \\
\text { processing }\end{array}$ & 1.37 & 2.58 & 4.16 & 6.73 & 20.51 & 33.15 & 53.58 \\
\hline Turbine and generators & 0.69 & 1.29 & 2.06 & 3.30 & 9.81 & 15.70 & 25.10 \\
\hline Control and instrumentation & 0.69 & 1.20 & 1.82 & 2.75 & 7.22 & 10.93 & 16.56 \\
\hline Miscellaneous plant equipment & 2.69 & 3.64 & 4.57 & 5.74 & 9.73 & 12.22 & 15.35 \\
\hline Water intake and discharge structures & 0.05 & 0.09 & 0.17 & 0.29 & 1.06 & 1.85 & 3.23 \\
\hline
\end{tabular}




\begin{tabular}{|c|c|c|c|c|c|c|c|}
\hline Cost Components (in millions of \$) & $\begin{array}{c}\text { 0.1 } \\
\text { MW }\end{array}$ & $\begin{array}{l}\text { 0.25 } \\
\text { MW }\end{array}$ & $\begin{array}{c}0.5 \\
\text { MW } \\
\end{array}$ & $\begin{array}{c}1 \\
\text { MW }\end{array}$ & $\begin{array}{c}5 \\
\text { MW } \\
\end{array}$ & $\begin{array}{c}10 \\
\text { MW }\end{array}$ & $\begin{array}{c}20 \\
\text { MW }\end{array}$ \\
\hline Engineering and design & 17.27 & 22.83 & 28.19 & 34.80 & 56.79 & 70.13 & 86.59 \\
\hline Construction services & 17.71 & 21.39 & 24.67 & 28.45 & 39.63 & 45.70 & 52.71 \\
\hline Indirect miscellaneous & 6.97 & 8.90 & 10.71 & 12.88 & 19.79 & 23.81 & 28.64 \\
\hline Contingencies & 0.49 & 0.81 & 1.19 & 1.74 & 4.23 & 6.19 & 9.07 \\
\hline Owner's cost & 17.66 & 23.10 & 28.29 & 34.66 & 55.53 & 68.02 & 83.33 \\
\hline Total OCs (millions \$) & 94.57 & 118.79 & 142.77 & 173.5 & 285.8 & 362.70 & 467.62 \\
\hline
\end{tabular}

The values seen in the table are very high, especially the ones that are highlighted. These high values are mainly due to small scaling factors used for cost components. As a result, estimates of the total investment cost are very high from the absence of economy of scale-which clearly does not work for smaller plants.

If we look closely at highlighted components, these are costs associated with land rights, engineering and design, construction services, owner's cost, and miscellaneous and contingencies. Each of these costs is significantly (i.e., 5 to 18 times) larger than the cost of major plant components like the reactor, turbine, and alternator. For large reactors, these costs are no more than half of the costs of plant components. The scaling factors might have made sense for large SRs - the highlighted cost components might be close for 300-1350 MW plants.

The next step is to explore each cost component and decide which factors would result in a sensible cost value. Table 5 provides a detailed justification for finding new scaling factors.

Table 5. Modification of scaling factors.

\begin{tabular}{|l|c|l|l|}
\hline $\begin{array}{c}\text { Cost } \\
\text { Component } \\
\text { in millions \$) }\end{array}$ & $\begin{array}{c}\text { Factor } \\
\text { Old }\end{array}$ & \multicolumn{1}{c|}{ Factor New } & \multicolumn{1}{c|}{ Justification } \\
\hline $\begin{array}{l}\text { Land, land } \\
\text { rights, site } \\
\text { utilities } \\
\text { Direct 1(D 1) }\end{array}$ & 0.07 & $\begin{array}{l}\text { For 0.1 MW: 0.7 } \\
\text { For 0.25 to 20 MW: } \\
60 \% \text { using 0.7 scaling } \\
\text { factor and 40\% from } \\
\text { the cost of 0.1 MW } \\
\text { plant. }\end{array}$ & $\begin{array}{l}\text { Proposed inherent safety means SRs do not need a large } \\
\text { exclusion zone. } \\
\text { SRs would only need plant boundary as an exclusion } \\
\text { zone. The plant could be sited within 35 acres (for a 12 } \\
\text { module NuScale plant) (Need to consider a similar cost } \\
\text { for SRs sized 5-20 MW). } \\
\text { Placed where the grid structure is already there or in a } \\
\text { microgrid configuration. } \\
\text { To preserve the economy of scale among 0.1-20 MW, we } \\
\text { consider 60\% cost from scaling and 40\% as size- } \\
\text { independent cost. }\end{array}$ \\
\hline $\begin{array}{l}\text { Buildings and } \\
\text { structures (D2) }\end{array}$ & 0.49 & 0.8 & $\begin{array}{l}\text { The total time to construct the buildings/plant is less, } \\
\text { resulting in fewer cost overruns. } \\
\text { The flexibility of siting means SRs can be placed } \\
\text { wherever feasible, and the cost for building and structures } \\
\text { can be optimized. }\end{array}$ \\
\hline $\begin{array}{l}\text { Steam } \\
\text { production and } \\
\text { discharge } \\
\text { processing (D3) }\end{array}$ & 0.69 & $\begin{array}{l}\text { Because modules are made in factories, components can } \\
\text { be easily transferred with any feasible mode of } \\
\text { transportation. Factory mass production plays a huge } \\
\text { role. }\end{array}$ \\
\hline
\end{tabular}




\begin{tabular}{|c|c|c|c|}
\hline $\begin{array}{c}\text { Cost } \\
\text { Component } \\
\text { (in millions \$) }\end{array}$ & $\begin{array}{l}\text { Factor } \\
\text { Old }\end{array}$ & Factor New & Justification \\
\hline & & & $\begin{array}{l}\text { Compared with the Massachusetts Institute of } \\
\text { Technology's cost target for reactor-module cost: } \\
5000 / \mathrm{kW} \text { without fuel loading. }\end{array}$ \\
\hline $\begin{array}{l}\text { Turbine and } \\
\text { generators (D4) }\end{array}$ & 0.68 & 0.8 & $\begin{array}{l}\text { Turbines and alternators are produced in a factory and } \\
\text { transported to the plant location. }\end{array}$ \\
\hline $\begin{array}{l}\text { Control and } \\
\text { instrumentation } \\
\text { (D5) }\end{array}$ & 0.6 & 0.7 & $\begin{array}{l}\text { The control and instrumentation setup is similar to large } \\
\text { plants. However, the cost could be optimized for smaller } \\
\text { plants with simpler control rooms. We are using } 0.7 \text { as } \\
\text { the scaling factor. }\end{array}$ \\
\hline $\begin{array}{l}\text { Miscellaneous } \\
\text { plant equipment } \\
\text { (D6) }\end{array}$ & 0.33 & $7 \%$ of $\mathrm{D} 3+\mathrm{D} 4+\mathrm{D} 5$ & $\begin{array}{l}\text { The scaling factor of } 0.3 \text { is very high. The cost of } \\
\text { miscellaneous plant equipment is usually taken as a } \\
\text { percentage of the cost of plant components. Based on } \\
\text { large plants, this cost is taken as } 7 \% \text { of known plant } \\
\text { equipment costs. }\end{array}$ \\
\hline $\begin{array}{l}\text { Water intake } \\
\text { and discharge } \\
\text { structures (D7) }\end{array}$ & 0.81 & 0.81 & $\begin{array}{l}\text { This factor is not very problematic. Thus, it can be } \\
\text { maintained as } 0.81 \text {. However, SRs may not even use } \\
\text { water for cooling; thus, large structures for water intake } \\
\text { may not be needed. }\end{array}$ \\
\hline $\begin{array}{l}\text { Engineering } \\
\text { and design } \\
\text { Indirect } 1 \text { (I 1) }\end{array}$ & 0.31 & 0.8 & $\begin{array}{l}\text { Engineering and design costs are significantly reduced } \\
\text { for the following reasons: } \\
\text { SRs are delivered directly from a factory and assembled. } \\
\text { (already a learned, engineered, and designed technology). } \\
\text { In SRs, the plant designs are driven by the factory- } \\
\text { produced components. In large reactors, plant design } \\
\text { decides the components, which are custom made. }\end{array}$ \\
\hline $\begin{array}{l}\text { Construction } \\
\text { services (I 2) }\end{array}$ & 0.21 & 0.8 & $\begin{array}{l}\text { The small construction schedule reduces the cost of } \\
\text { construction services. } \\
\text { Due to the simpler design, assembly is faster. }\end{array}$ \\
\hline $\begin{array}{l}\text { Indirect } \\
\text { miscellaneous } \\
\text { (I 3) }\end{array}$ & 0.27 & $20 \%$ of I $1+\mathrm{I} 2$ & $\begin{array}{l}\text { Due to the short construction schedule and factory- } \\
\text { produced components, the construction cost will be less } \\
\text { uncertain. Thus, the miscellaneous cost is less in SRs. It } \\
\text { is usually taken as a certain percentage of total indirect } \\
\text { costs. Based on what is known for large plants, this cost } \\
\text { is } 20 \% \text { of known indirect costs (I 1+I 2). }\end{array}$ \\
\hline Contingencies & 0.55 & $3.5 \%$ of $\mathrm{D}+\mathrm{I}$ & $\begin{array}{l}\text { Reduced time for production, site preparation, and } \\
\text { installation (due to a firmer construction schedule and } \\
\text { factory-produced components) brings better certainty to } \\
\text { cost estimates, lowering the contingency cost. Further } \\
\text { confidence comes from field testing-e.g., at INL's field } \\
\text { test site. Contingencies can be considered a percentage of } \\
\text { total direct and indirect costs. Based on what has been } \\
\text { seen in large plants, this cost is defined as } 3.5 \% \text { of direct } \\
\text { and indirect costs. }\end{array}$ \\
\hline Owner's cost & 0.29 & $12 \%$ of total OCs. & $\begin{array}{l}\text { The owner's cost includes all the costs, including design } \\
\text { and licensing that occur before the construction starts. } \\
\text { For large plants, it perhaps made sense to have similar } \\
\text { owner costs for all sizes, but for SRs, they cannot be very } \\
\text { high: only } 12 \% \text { of total OCs. }\end{array}$ \\
\hline
\end{tabular}


With these updates in the scaling factor, the total OC for SR is calculated in Table 6.

Table 6. New costs with new scaling factors.

\begin{tabular}{|l|l|l|l|l|l|l|l|}
\hline $\begin{array}{l}\text { Cost Components } \\
\text { (Millions \$) }\end{array}$ & $\mathbf{0 . 1 M W}$ & $\mathbf{0 . 2 5} \mathbf{M W}$ & $\mathbf{0 . 5 M W}$ & $\mathbf{1 M W}$ & $\mathbf{5 M W}$ & $\mathbf{1 0 M W}$ & $\mathbf{2 0 M W}$ \\
\hline $\begin{array}{l}\text { Land, land rights, } \\
\text { site utilities }\end{array}$ & 0.1544 & 0.2377 & 0.3475 & 0.5260 & 1.4940 & 2.3885 & 3.8415 \\
\hline $\begin{array}{l}\text { Buildings and } \\
\text { structures }\end{array}$ & 0.3664 & 0.7627 & 1.3279 & 2.3120 & 8.3784 & 14.5877 & 25.3986 \\
\hline $\begin{array}{l}\text { Steam production } \\
\text { and discharge } \\
\text { processing }\end{array}$ & 0.5818 & 1.2110 & 2.1085 & 3.6711 & 13.3036 & 23.1629 & 40.3289 \\
\hline $\begin{array}{l}\text { Turbine and } \\
\text { generators }\end{array}$ & 0.2600 & 0.5411 & 0.9421 & 1.6403 & 5.9442 & 10.3494 & 18.0193 \\
\hline $\begin{array}{l}\text { Control and } \\
\text { instrumentation }\end{array}$ & 0.3088 & 0.5864 & 0.9526 & 1.5475 & 4.7742 & 7.7558 & 12.5993 \\
\hline $\begin{array}{l}\text { Miscellaneous plant } \\
\text { equipment }\end{array}$ & 0.0805 & 0.1637 & 0.2802 & 0.4801 & 1.6815 & 2.8888 & 4.9663 \\
\hline $\begin{array}{l}\text { Water intake and } \\
\text { discharge structures }\end{array}$ & 0.0434 & 0.0912 & 0.1599 & 0.2804 & 1.0325 & 1.8101 & 3.1735 \\
\hline $\begin{array}{l}\text { Engineering and } \\
\text { design }\end{array}$ & 0.3293 & 0.6854 & 1.1933 & 2.0777 & 7.5293 & 13.1092 & 22.8245 \\
\hline $\begin{array}{l}\text { Construction } \\
\text { services }\end{array}$ & 0.1535 & 0.3195 & 0.5563 & 0.9685 & 3.5099 & 6.1111 & 10.6400 \\
\hline $\begin{array}{l}\text { Indirect } \\
\text { miscellaneous }\end{array}$ & 0.0966 & 0.2010 & 0.3499 & 0.6092 & 2.2078 & 3.8441 & 6.6929 \\
\hline Contingencies & 0.0831 & 0.1680 & 0.2876 & 0.4939 & 1.7449 & 3.0103 & 5.1970 \\
\hline Owner's cost & 0.3352 & 0.6774 & 1.1599 & 1.9918 & 7.0364 & 12.1388 & 20.9566 \\
\hline $\begin{array}{l}\text { Total OCs (in } \\
\text { Millions \$) }\end{array}$ & 2.7929 & 5.6449 & 9.6657 & 16.5985 & 58.64 & 101.16 & 174.64 \\
\hline $\begin{array}{l}\text { Specific OCs } \\
\text { (\$/kW) }\end{array}$ & $\mathbf{2 7 9 2 9}$ & $\mathbf{2 2 5 8 0}$ & $\mathbf{1 9 3 3 1}$ & $\mathbf{1 6 5 9 8}$ & $\mathbf{1 1 7 2 7}$ & $\mathbf{1 0 1 1 6}$ & $\mathbf{8 7 3 2}$ \\
\hline
\end{tabular}

\subsubsection{Initial fuel-load cost}

Table 7 provides the front-end fuel pricing for 2017 as provided by the World Nuclear Association website [54].

Table 7. Fuel cost of $1 \mathrm{~kg}$ of uranium as $\mathrm{UO}_{2}$ fuel.

\begin{tabular}{|l|c|l|c|}
\hline Process & Amount Required $\times$ Price & Cost & Proportion of Fuel \\
\hline Uranium & $8.9 \mathrm{~kg} \mathrm{U} \mathrm{O}_{8} \times \$ 68$ & $\$ 605$ & $43 \%$ \\
\hline Conversion & $7.5 \mathrm{~kg} \mathrm{U} \times \$ 14$ & $\$ 105$ & $8 \%$ \\
\hline Enrichment & $7.3 \mathrm{SWU} \times \$ 52$ & $\$ 380$ & $27 \%$ \\
\hline Fuel fabrication & per kg & $\$ 300$ & $22 \%$ \\
\hline Total & & $\mathbf{\$ 1 , 3 9 0}$ & \\
\hline
\end{tabular}

Full form: SWU (separative work units: to separate the isotopes) 
Considering 5 years for the refueling cycle, thermal efficiency of 33\%, and fuel burnup rate of $50 \mathrm{GWdt} / \mathrm{ton}$, the following cost of first-core loading is estimated. The following cost in Table 8 also includes a $50 \%$ contingency in fuel costs.

Table 8. Front-end fuel loading costs.

\begin{tabular}{|c|c|c|c|}
\hline $\begin{array}{c}\text { Plant Size } \\
(\mathbf{K W})\end{array}$ & $\begin{array}{c}\text { Thermal Rating } \\
(\mathbf{k W t h})\end{array}$ & $\begin{array}{c}\text { Core Size } \\
(\mathbf{k g})\end{array}$ & $\begin{array}{c}\text { Total Cost } \\
\mathbf{( \$ )}\end{array}$ \\
\hline 100 & 300 & 10.95 & 22830.75 \\
\hline 250 & 750 & 27.375 & 57076.875 \\
\hline 500 & 1500 & 54.75 & 114153.75 \\
\hline 1000 & 3000 & 109.5 & 228307.5 \\
\hline 5000 & 15000 & 547.5 & 1141537.5 \\
\hline 10000 & 30000 & 1095 & 2283075 \\
\hline 20000 & 60000 & 2190 & 4566150 \\
\hline
\end{tabular}

\subsubsection{Final cost considering IDC}

Because the modules will be produced in a factory, the construction of a NOAK plant will be completed within 2-3 years. A flat $6 \%$ IDC is assumed in this calculation. In detailed calculation, IDC must be distributed monthly or quarterly, as is done in G4ECONS.

Table 9. Final costs considering IDC.

\begin{tabular}{|l|r|r|r|}
\hline Size (kW) & Overnight + Fuel Cost $\mathbf{( \$ )}$ & Investment Cost $\mathbf{( \$ )}$ & Specific Cost (\$/kW) \\
\hline 100 & 2815766.9 & 2984713 & 29847.13 \\
\hline 250 & 5702019.3 & 6044140.4 & 24176.56 \\
\hline 500 & 9779877.1 & 10366669.7 & 20733.34 \\
\hline 1000 & 16826796.5 & 17836404.3 & 17836.40 \\
\hline 5000 & 59778287.2 & 63364984.5 & 12673 \\
\hline 10000 & 103439518.2 & 109645889.3 & 10964.59 \\
\hline 20000 & 179204607.9 & 189956884.4 & 9497.84 \\
\hline
\end{tabular}

\subsubsection{Installation Costs}

Installation costs include land rights and site utilities, building and structures, engineering and design, and construction services. Note that this cost is already part of the investment cost.

\subsubsection{Install Size/Unit Size}

The reactor unit sizes ranging from $100 \mathrm{~kW}$ to $20 \mathrm{MW}$ are considered for the applications highlighted in this report [55].

\subsubsection{O\&M Costs}

Fuel-based O\&M costs include the front- and back-end of every fuel cycle, divided over the refueling cycle. The back end of the fuel cycle, including used-fuel storage or disposal in a waste repository, contributes up to $10 \%$ of the overall costs per kilowatt hour, or less if there is direct disposal of used fuel rather than reprocessing. The $\$ 26$ billion U.S. used-fuel program is funded by a $0.1 \mathrm{cent} / \mathrm{kWh}$ levy.

Overall, Reference [56] gives an idea of the total fuel-based O\&M cost to be \$6-9/MWh. The nonfuel cost is estimated to be $\$ 16-27 / \mathrm{MWh}$. The high-end figure of $\$ 27 / \mathrm{MWh}$ is multiplied further by 1.5 to account for costs that cannot be reduced linearly with size (e.g., technical support staff). 
The O\&M cost for the preliminary assessment is taken as $\mathbf{\$ 5 0 / M W h}$ for all sizes. This must be analyzed in more detail.

\subsubsection{Electric Efficiency}

The fuel is uranium, which is enriched and kept in the core. Considering the average burnup rate of $50 \mathrm{GWdt} /$ ton, the electrical efficiency with respect to fuel would be $400,000 \mathrm{kWh} / \mathbf{k g}$ of uranium.

\subsubsection{Heat-to-Power Ratio}

We have seen this ratio from as low as 1:0.25 to as much as 1:0.48. Smaller reactors are expected to have low efficiency. SRs are shown to be in the range of 1:0.28 to 1:0.42. The ratio 3:1 is commonly used.

\subsubsection{Lifetime}

SRs are estimated to have plant life of 40-60 years [55].

\subsubsection{Minimum Loading}

NuScale reactor units reportedly have a minimum loading capacity of up to $20 \%$ for normal operation [57]. The lower limit of the power range, at which the reactor is under automatic control, occurs at $15 \%$ of full power. For normal operations, it is fair to assume the minimum limits of reactor units to be $\mathbf{2 0 - 2 5 \%}$.

\subsubsection{Minimum Up- and Downtimes}

In [58], the uptime and downtime of 12 hours each were assumed and used for the assessment for DHR-400 and NuScale plants. This aligns well with the operational procedure of the NuScale plant [57]. Although it is not technically and economically recommended to constantly turn on and off the reactors, that they can be turned off or on after 12 hours of opposite status is assumed.

\subsubsection{Decommissioning Costs}

Decommissioning costs are about $9-15 \%$ of initial capital costs for a nuclear power plant. When discounted over the lifetime of the plant, they contribute only a few percent to the investment cost and even less to the generation cost. In the case of large NPPs, they account for $0.1-0.2$ cents $/ \mathrm{kWh}$, which is no more than $5 \%$ of the cost of the electricity produced. In the case of SRs, it can be assumed to be up to $25 \%$.

Table 10. Decommissioning costs.

\begin{tabular}{|l|r|}
\hline Size $(\mathbf{k W})$ & Decommissioning Cost $\mathbf{( \$ \mathbf { k W } )}$ \\
\hline 100 & 7461.782402 \\
\hline 250 & 6044.14043 \\
\hline 500 & 5183.334843 \\
\hline 1000 & 4459.101084 \\
\hline 5000 & 3168.249223 \\
\hline 10000 & 2741.147234 \\
\hline 20000 & 2374.461055 \\
\hline
\end{tabular}

\subsubsection{Waste-Handling Costs}

Spent fuels can either be reprocessed or directly disposed of. In Table 11, the assumption is a directdisposal alternative that includes storage, conditioning, transportation, and a deep geologic repository (DGR). 
Table 11. Used-fuel disposal steps and costs.

\begin{tabular}{|c|c|}
\hline Process Step & Unit Cost (\$/kgHM*) \\
\hline Wet Storage & 331 \\
\hline Dry Storage & 113 \\
\hline Waste Conditioning & 110 \\
\hline Transportation & 125 \\
\hline DGR & 718 \\
\hline Total & 1397 \\
\hline
\end{tabular}

* KgHM: kilogram heavy metals

The total backend cost of uranium fuel (for each refueling) is calculated in Table 12 .

Table 12. Back-end costs of used fuels.

\begin{tabular}{|c|c|c|c|c|}
\hline $\begin{array}{c}\text { Plant Size } \\
(\mathbf{k W})\end{array}$ & $\begin{array}{l}\text { Core Size } \\
\text { (kgHM) }\end{array}$ & $\begin{array}{c}\text { Total Cost } \\
\text { 5-yrs (\$) }\end{array}$ & $\underset{\$ / y r}{\operatorname{In}}$ & $\underset{\text { \$/MWh }}{\text { In }}$ \\
\hline 100 & 10.95 & 15297.15 & 3059.43 & \multirow{7}{*}{3.4925} \\
\hline 250 & 27.375 & 38242.875 & 7648.58 & \\
\hline 500 & 54.75 & 76485.75 & 15297.15 & \\
\hline 1000 & 109.5 & 152971.5 & 30594.3 & \\
\hline 5000 & 547.5 & 764857.5 & 152971.5 & \\
\hline 10000 & 1095 & 1529715 & 305943 & \\
\hline 20000 & 2190 & 3059430 & 611886 & \\
\hline
\end{tabular}

Waste handling costs can be taken as $\$ 3.5 / \mathrm{MWh}$. Adding a $\$ 1 / \mathrm{MWh}$ surcharge to the Nuclear Waste Fund, the total waste-handling cost comes out as $\$ 4.5 / \mathrm{MWh}$.

\subsubsection{Approach 2}

For large reactors: payment to the Nuclear Waste Fund: \$1/MWh (fixed) and for storage and packaging another $\$ 1 / \mathrm{MWh}$. Total: \$2/MWh.

For smaller reactors: The packaging and storage could be doubled, and the total waste-handling cost would be $\$ 3 / \mathrm{MWh}$. More-detailed assessment can also be conducted using the COA method. (In some reports it is given up to $\$ 5 / \mathrm{MWh}$.) 


\section{SR MICROGRID PROJECT-NEXT STEPS}

This report provides context and background information for the Small Reactor Microgrid project at INL. With the continued support and funding from the DOE, Office of Electricity (OE) in FY 2022, this project will realize concrete deliverables to advance SR microgrids.

\subsection{Next Steps in Realizing the Potential of SR Microgrids and the Realization of Zero-Carbon Goals}

The scope of the existing project will be extended to include a detailed technoeconomic analysis of specific use cases identified in the initial scope of work, based on the best available data on microreactor performance and cost.

A proxy model of a microreactor in a microgrid with renewable generation and storage will be developed. This is a preliminary, generic model of SR-integrated microgrids that reflects the unique technical-characteristic datasets and SR-integrated designs for microgrids and their interaction with the grid. This model will be used for cost minimization and GHG reduction in multiple configurations for multiple scenarios. It will establish metrics for a path towards a cost-competitive and zero-carbon microgrid, fully integrated with the grid. This will be done for microreactor modules for multiple use cases in many configurations of DER.

INL will develop both a specification and data for a microreactor module to be added to the XENDEE microgrid decision support platform that couples detailed electrical-power system analysis with financial optimization, as well as metrics for GHG emissions.

Ongoing technical activities to advance SR microgrids will include:

- Continuing to collect data for SR dynamic models and generator controls

- Aligning with the specification of MARVEL/Microreactor Agile Non-nuclear Experimental Testbed

(MAGNET) reactor test platforms to specify necessary next steps toward demonstration at INL

- Conducting dynamic modeling and simulation of microreactors in microgrids

- Identifying operational issues related to microgrids with microreactor provisioning of grid services.

INL will pursue these activities with the constant awareness of the implications for the deployment of SR and their contribution to net-zero carbon microgrids as they transition to zero-carbon microgrids. 


\section{REFERENCES}

[1] Federal Energy Regulatory Commission (FERC) and North American Electric Reliability (NERC), "Outages and Curtailments During the Southwest Cold Weather Event of February 1-5, 2011: causes and recommendations," 2011.

[2] K. Hansen, "Extreme Winter Weather Causes U.S. Blackouts,” NASA Earth Obs., pp. 1-5, 2021.

[3] IEEE PES, IEEE 2030.7-2017 Standard for the Specification of Microgrid Controllers. 2018.

[4] International Atomic Energy Agency (IAEA), Advances in Small Modular Reactor Technology Developments. Vienna, Austria: IAEA, 2018.

[5] Toshiba-CRIEPI, "Super-Safe, Small and Simple Reactor (4S, Toshiba Design)," Toshiba, no. 1, pp. 1-38, 2013, [Online]. Available:

http://joi.jlc.jst.go.jp/JST.Journalarchive/materia1994/44.24?from=CrossRef.

[6] C. Colbert, "Overview of NuScale Design,” Tech. Meet. Technol. Assess. SMRs Near-Term Deploy., pp. 1-47, 2013.

[7] Microreactor Program (MRP), "Microreactor Applications Research Validation and Evaluation Project (MARVEL)," Idaho Falls, Idaho.

[8] L. M. Boldon and P. Sabharwall, "Small Modular Reactor : First-of-a-Kind ( FOAK ) and Nth-ofa-Kind ( NOAK ) Economic Analysis Idaho National Laboratory Summer 2014 Report," no. August, p. 18, 2014, [Online]. Available: http://www.inl.gov.

[9] B. McDowell and D. Goodman, "Advanced Nuclear Reactor Plant Parameter Envelope and Guidance,” National Reactor Innovation Center (NRIC), NRIC-21-ENG-0001; PNNL-30992, 2021.

[10] Microreactor Program (MRP), “A Microreactor Program Plan for The Department of Energy: An Integrated, Strategic Program Plan for the Research and Development Supporting Demonstration and Deployment of Nuclear Microreactors," Idaho Falls, Idaho, INL/EXT-20-58919, Revision 2, 2021.

[11] Aboriginal Affairs and Northern Development Canada and Natural Resources Canada, "Status of Remote/Off-grid Communities in Canada," Natural Resources Canada, Ottawa. doi:

$10.3390 / \mathrm{su} 4081806$.

[12] C. P. Underwood, J. Ramachandran, R. D. Giddings, and Z. Alwan, "Renewable-energy clusters for remote communities," Appl. Energy, vol. 84, no. 6, pp. 579-598, 2007, doi: https://doi.org/10.1016/j.apenergy.2007.01.017.

[13] V. Tulkki, E. Pursiheimo, T. J. Lindroos, and V. Sahlberg, "Small Modular Reactors as a part of a District Heating System," Trans. Am. Nucl. Soc., Vol. 118, Philadelphia, Pennsylvania, June 17 21, 2018, vol. 118, pp. 685-687, 2018.

[14] V. Tulkki, E. Pursiheimo, and T. Lindroos, "District Heat with Small Modular Reactors (SMR)," 2017.

[15] B. Poudel and R. Gokaraju, "Small Modular Reactor (SMR) Based Hybrid Energy System for Electricity and District Heating," IEEE Trans. Energy Convers., p. 1, 2021, doi:

10.1109/TEC.2021.3079400.

[16] B. Poudel and R. Gokaraju, "Optimal Operation of SMR-RES Hybrid Energy System for Electricity and District Heating," IEEE Trans. Energy Convers., p. 1, 2021, doi:

10.1109/TEC.2021.3080698. 
[17] J. Hazra, M. Padmanaban, F. Zaini, and L. C. De Silva, "Congestion relief using grid scale batteries,” 2015 IEEE Power Energy Soc. Innov. Smart Grid Technol. Conf. ISGT 2015, vol. 2, no. 1, 2015, doi: 10.1109/ISGT.2015.7131789.

[18] H. Haas, "Basic Congestion Concepts," 2019.

[19] L. Bai, J. Wang, C. Wang, C. Chen, and F. Li, "Distribution Locational Marginal Pricing (DLMP) for Congestion Management and Voltage Support," IEEE Trans. Power Syst., vol. 33, no. 4, pp. 4061-4073, 2018, doi: 10.1109/TPWRS.2017.2767632.

[20] California ISO, “Market price maps," Open Access Same Time Information, 2021. www.caiso.com/PriceMap/Pages/default.aspx.

[21] A. D. Del Rosso and S. W. Eckroad, "Energy storage for relief of transmission congestion," IEEE Trans. Smart Grid, vol. 5, no. 2, pp. 1138-1146, 2014, doi: 10.1109/TSG.2013.2277411.

[22] United States Envirionmental Protection Agency (EPA), "Inventory of U.S. Greenhouse Gas Emissions and Sinks: 1990-2019," EPA 430-R-21-005, 2019.

[23] The Massachusetts Division of Energy Resources, "Electric Vehicle Charging Equipment Installation Guide: An Overview of Recommendations and Requirements," 2000.

[24] ACEA - European Automobile Manufacturers Association, "ACEA position and recommendations for the standardization of the charging of electrically chargeable vehicles," vol. 2010, no. August, pp. 1-13, 2011.

[25] Tesla, "Supercharger," tesla.com..

[26] A. I. Miller and R. B. Duffey, "Integrating large-scale Co-generation of hydrogen and electricity from wind and nuclear sources (NUWINDC)," 2007, doi: 10.1109/EICCCC.2006.277187.

[27] M. F. Ruth, O. R. Zinaman, M. Antkowiak, R. D. Boardman, R. S. Cherry, and M. D. Bazilian, "Nuclear-renewable hybrid energy systems: Opportunities, interconnections, and needs," Energy Convers. Manag., vol. 78, pp. 684-694, 2014, doi: 10.1016/j.enconman.2013.11.030.

[28] G. Locatelli, S. Boarin, A. Fiordaliso, and M. E. Ricotti, "Load following of Small Modular Reactors (SMR) by cogeneration of hydrogen: A techno-economic analysis," Energy, vol. 148, pp. 494-505, 2018, doi: 10.1016/j.energy.2018.01.041.

[29] R. Doctor, D. Matonis, and R. Lyczkowski, "High-Temperature Electrolysis," in DOE Solar Hydrogen Workshop, 2004, no. November, [Online]. Available:

https://www1.eere.energy.gov/solar/pdfs/doctor.pdf.

[30] J. C. Kennedy et al., "Special Purpose Application Reactors: Systems Integration Decision Support,” INL/EXT-18-51369, Sep. 2018.

[31] Naval Sea Systems Command, "Naval Ships' Technical Manual Distribution Systems," Naval Sea Systems Command, S9086-KY-STM-010, Mar. 2005.

[32] J. Marqusee, C. Schultz, and D. Robyn, "Power Begins at Home: Assured Energy for U.S. Military Bases,” Noblis, 2017.

[33] A. Klauber et al., Airport Microgrid Implementation Toolkit. National Academies Press, 2021.

[34] Schatz Energy Research Center, "Redwood Coast Airport Renewable Energy Microgrid Fact Sheet," 2020.

[35] M. Marshall and J. Zoellick, "Redwood Coast Airport Microgrid : Advancing a resilient and clean energy future," in Clean Coalition, 2020, no. September.

[36] D. Proctor, "Gas, Solar Will Power Pittsburgh Airport," Power Magazine, pp. 1-6, Jul. 2021. 
[37] MLIT Japan, “Airport electric power facilities," 2021. https://www.mlit.go.jp/koku/15_hf_000085.html (accessed May 14, 2021).

[38] MIC Japan, “Aeronautical Communications,” 2021. https://www.tele.soumu.go.jp/e/adm/system/satellit/air/ (accessed Jun. 16, 2021).

[39] G. Velidi and U. Guven, "Usage of nuclear power as a powerful source for space stations and for space development missions," in 62nd International Astronautical Congress (IAC), 2011, vol. 8, pp. 6784-6791.

[40] National Aeronautics and Space Administration International (NASA), "International Space Station Basics," NASA, EW-2007-02-150-HQ, 2010.

[41] Glenn Research Center, "Powering the Future: NASA Glenn Contributions to the International Space Station (ISS) Electrical Power System,” NASA, Cleveland, Ohio, FS-2000-11-006-GRC, 2000. doi: 10.4271/2000-01-3608.

[42] D. R. Williams, "Mars Fact Sheet," NASA Space Science Data Coordinated Archive. Nov. 2020.

[43] E. Hussein et al., "A case study on introducing small modular reactors into a new non-nuclear jurisdiction," 2018, doi: 10.1007/BF01118672.

[44] K. Söderholm, "Challenges of SMR Licensing Practices," AECL Nucl. Rev., vol. 1, no. 2, pp. 19-31, 2012, doi: 10.12943/anr.2012.00015.

[45] B. E. R. Lulik, D. DeMontigny, and E. M. A. Hussein, "Is an exclusion zone needed for a small modular reactor?," Jun. 2018.

[46] G. T. Mays, R. J. Belles, O. A. Omitaomu, and W. P. Poore, "Application of spatial data modeling and geographical information systems (GIS) for identification of potential siting options for small modular reactors," 2013.

[47] IAEA, "Non-baseload Operation in Nuclear Power Plants: Load Following and Frequency Control Modes of Flexible Operation," Vienna, Austria, NP-T-3.23, 2018. [Online]. Available: http://www.iaea.org/Publications/index.html.

[48] K. Joshi, B. Poudel, and R. R. Gokaraju, "Investigating small modular reactor's design limits for its flexible operation with photovoltaic generation in microcommunities," J. Nucl. Eng. Radiat. Sci., vol. 7, no. 3, pp. 1-10, 2021, doi: 10.1115/1.4048896.

[49] Nuclear Energy Agency, "Technical and Economic Aspects of Load Following with Nuclear Power Plants," Nuclear Development, Paris, France, 2011. [OnlError! Hyperlink reference not valid.ailable: www.oecd-nea.org.

[50] K. Joshi, B. Poudel, and R. Gokaraju, "Exploring Synergy Among NEW Generation Technologies: Small Modular Rector, Energy Storage and Distributed Generation - a Strong Case for Remote Communities," J. Nucl. Eng. Radiat. Sci., Oct. 2019, doi: 10.1115/1.4045122.

[51] Gen-IV International Forum, "Cost Estimating Guidelines for Generation IV Nuclear Energy Systems," Organisation for Economic Co-Operation and Development (OECD) Nuclear Energy Agency, 4.2, 2007. [Online]. Available: https://www.gen4.org/gif/upload/docs/application/pdf/2013-09/emwg_guidelines.pdf.

[52] IAEA, "Status of Small Reactor Designs Without On-Site Refuelling," Vienna, Austria, IAEATECDOC-1536, 2007.

[53] "Final Safety Analysis Report: Site Characteristics and Site Parameters," in NuScale Standard Plant Design Certification Application, NuScale Power LLC, Corvallis, Oregon, USA, Part 2-Tier 2, Revision 5, Jul. 2020. 
[54] World Nuclear Association, "Economics of nuclear power," Nuclear Power Economics| Nuclear Energy Costs, Mar. 2021. https://www.world-nuclear.org/information-library/economicaspects/economics-of-nuclear-power.aspx.

[55] IAEA, Advances in Small Modular Reactor Technology Developments, 2020th ed. Vienna, Austria: IAEA, 2020.

[56] V. Kuznetsov, A. Lokhov, R. Cameron, and M. Cometto, "Current Status, Technical Feasibility, and Economics of Small Nuclear Reactors,” 2011.

[57] "Final Safety Analysis Report (Rev. 2) - Part 02 - Chapter 10 - Steam and Power Conversion System,” NuScale Power LLC, Corvallis, Oregon, 2018.

[58] T. J. Lindroos, E. Pursiheimo, V. Sahlberg, and V. Tulkki, "A techno-economic assessment of NuScale and DHR-400 reactors in a district heating and cooling grid," Energy Sources, Part B Econ. Plan. Policy, vol. 14, no. 1, pp. 13-24, 2019, doi: 10.1080/15567249.2019.1595223.

[59] OECD, The Economics of the Back End of the Nuclear Fuel Cycle, NEA No. 7061. Paris: OECD Publishing, 2013.

[60] The University of Chicago, "The Economic Future of Nuclear Power: A Study Conducted at the University of Chicago," 2004.

[61] R. Rosner, S. Goldberg, J. S. Hezir, and E. M. Davis, "Analysis of GW-Scale Overnight Capital Costs,” Energy Policy Institute at Chicago (EPIC), 2011. [Online]. Available: http://csis.org/files/attachments/111129_EPIC_OvernightCost_Report.pdf.

[62] World Nuclear Association, "The Economics of Nuclear Power (Updated December 2018)," World Nucl. Assoc., no. November, p. 16, 2018.

[63] U.S. DOE Nuclear Energy Research Advisory Committee (NERAC) and Generation IV International Forum, "A Technology Roadmap for Generation IV Nuclear Energy Systems: Ten Nations Preparing Today for Tomorrow's Energy Needs," 2002. [Online]. Available:

http://www.gen-

4.org/PDFs/GenIVRoadmap.pdf\%5Cnhttp://scholar.google.com/scholar?hl=en\&btnG=Search\&q =intitle:A+Technology+Roadmap+for+Generation+IV+Nuclear+Energy+Systems\#0.

[64] M. Moore, A. Korinny, D. Shropshire, and R. Sadhankar, "Benchmarking of nuclear economics tools,” Ann. Nucl. Energy, vol. 103, pp. 122-129, 2017, doi: 10.1016/j.anucene.2017.01.020.

[65] J. Green, "SMR cost estimates, and costs of SMRs under construction," Nuclear Monitor, no. 872-873, 2019.

[66] Economic and Finance Working Group, "SMR Roadmap,” 2018.

[67] G. Locatelli and M. Mancini, "Competitiveness of small-medium, new generation reactors: A comparative study on decommissioning," J. Eng. Gas Turbines Power, vol. 132, no. 10, pp. 1-8, 2010, doi: 10.1115/1.4000613.

[68] B. Mignacca and G. Locatelli, "Economics and finance of Small Modular Reactors: A systematic review and research agenda," Renew. Sustain. Energy Rev., vol. 118, no. July 2019, p. 109519, 2020, doi: 10.1016/j.rser.2019.109519.

[69] L. R. Christensen and W. H. Greene, "Economies of Scale in U.S. Electric Power Generation," J. Polit. Econ., vol. 84, no. 4, Part 1, pp. 655-676, 1976, doi: 10.1086/260470.

[70] IAEA, "Approaches for Assessing the Economic Competitiveness of Small and Medium Sized Reactors," Vienna, Austria, NP-T-3.7, 2013. 
[71] M. Moore, "The Economics of Very Small Modular Reactors in the North," in 4th International Technical Meeting on Small Reactors (ITMSMR-4), 2016, p. 8.

[72] B. Mignacca and G. Locatelli, "Economics and finance of Small Modular Reactors: A systematic review and research agenda," Renew. Sustain. Energy Rev., vol. 118, no. September 2019, p. 109519, 2020, doi: 10.1016/j.rser.2019.109519.

[73] R. Rosner and S. Goldberg, "Small Modular Reactors - Key to Future Nuclear Power Generation in the U.S.," no. November. Energy Policy Institute at Chicago (EPIC), 2011.

[74] G. A. Black, F. Aydogan, and C. L. Koerner, "Economic viability of light water small modular nuclear reactors: General methodology and vendor data," Renew. Sustain. Energy Rev., vol. 103, no. January, pp. 248-258, 2019, doi: 10.1016/j.rser.2018.12.041.

[75] Nuclear Energy Agency (NEA), "Small Modular Reactors: Nuclear Energy Market Potential for Near-term Deployment," 2016.

[76] OECD, “The economics of nuclear fuel cycle,” 1995. doi: 10.1016/0140-6701(95)93122-8.

[77] Nuclear-power.net, "Fuel Burnup," Definition, Calculation \& Units | nuclear-power.ne, 2018..

[78] D. T. Ingersoll, C. Colbert, Z. Houghton, R. Snuggerud, J. W. Gaston, and M. Empey, “Can Nuclear Power and Renewables be Friends?," in Proceedings of ICAPP, 2015, p. 9. 


\section{Annex A \\ Literature Study for SR Technoeconomic Modeling}


Page intentionally left blank 


\section{Annex A \\ Literature Study for SR Technoeconomic Modeling \\ A-1. NUCLEAR POWER PLANT LIFE-CYCLE COST}

Due to the large investment necessary for conventional NPPs, very few investors have the opportunity to participate in the energy markets with nuclear power. The low overall capital costs of SRs provide an opportunity for broader demographics of investors to participate in nuclear energy markets. The specific cost $(\$ / \mathrm{kW})$ of initial SRs is expected to be very high, but with learning and considering their eventual transition to factory production, the cost is expected to be competitive with non-nuclear clean-generation technologies.

The life-cycle cost includes all the expenses associated with an NPP, including its development, operation and maintenance, fuel production and waste handling, and decontamination and decommissioning of the plant. Figure A-1 shows the breakdown of nuclear life-cycle costs with different discount rates. The investment cost, already largest in conventional NPPs, represents an even larger part of the life-cycle cost if a larger discount rate is used. Decommissioning expenses, on the other hand, occur at the end of the nuclear life and represent a very small portion of the total life-cycle cost. The fuel cost in some references is considered a part of O\&M expenses. The discussion below focuses on estimating the life-cycle cost of SRs.

Discount rate: $5 \%$

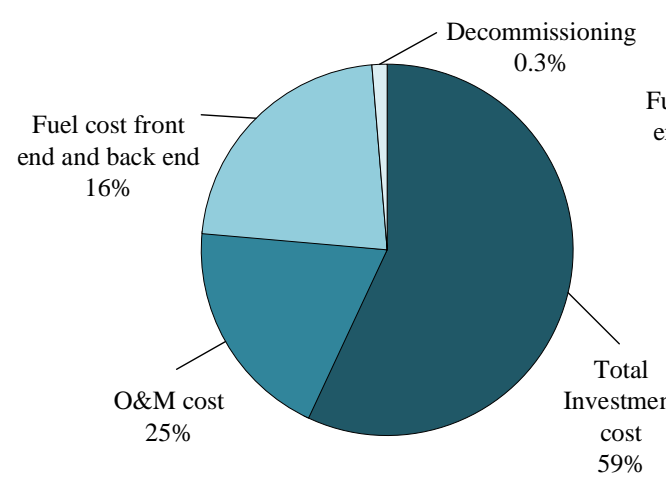

Discount rate: $10 \%$

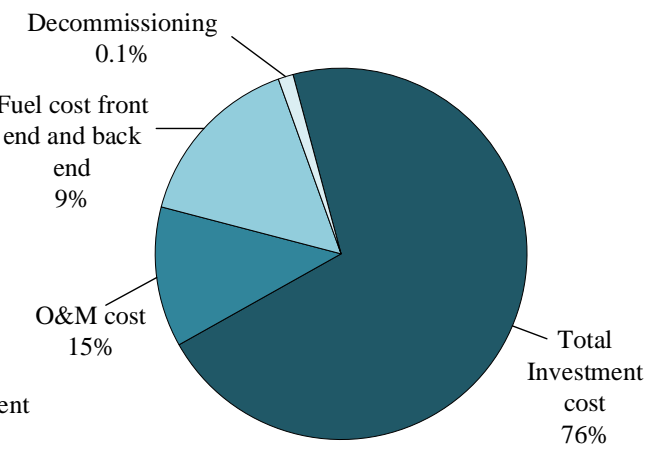

Figure A-1. Nuclear life-cycle cost with different discount rates [59].

\section{A-1.1 Capital Cost}

Capital cost represents the major portion of the total life-cycle cost of an NPP. It includes the expenses starting from the engineering design of the plant up to the point when it starts producing power commercially. The first SRs have yet to be developed and deployed. SRs propose a significant shift in the deployment approach from that of traditional, large reactors. Due to this, the cost models of SRs are still uncertain. However, experience with large nuclear power plants, although not entirely relatable to smaller plants, provides a good starting point for estimating the capital costs of SRs.

In 2004, the University of Chicago conducted a study investigating capital-cost estimates of new nuclear technologies and compared their economic competitiveness against other generation technologies [60]. The analysis of the mature new advanced designs of NPPs showed that incentives are necessary to support the nuclear industry if it is to compete in the market with GHG-emitting generation technologies such as coal and natural gas. The analysis demonstrated that, in the absence of federal financial incentives 
for the nuclear industry, the new nuclear plants have an LCOE-i.e., the price required to cover operating and capital costs - in a range of \$47-71/MWh. This price range exceeds projections of \$33-41 for coalfired plants and \$35-45 for gas-fired plants. The study was influential in encouraging the U.S. Congress to bring new incentives for the nuclear industry.

The capital costs reported for new generation NPPs by different sources have not been comparable, adding to the uncertainty for investors. Under a DOE program for promoting NPPs, a feasibility study carried out by the Tennessee Valley Authority for two advanced boiling water reactors (ABWRs) showed that twin $1371 \mathrm{MW}$ ABWRs would cost $\$ 1611$ per kilowatt or if they were uprated to $1465 \mathrm{MW}$ each, $\$ 1535 / \mathrm{kW}$. They could be built in 40 months. Since that study, the capital cost of NPPs has increased significantly, and companies currently are indicating a range of $\$ 5500-8100 / \mathrm{kW}$.

The current cost estimates for Generation IV NPPs in regulatory filings are based on four NPPs: Vogtle 3 and 4, proposed in Georgia, South Carolina Electric and Gas's Virgil C. Summer 2 and 3, Progress Energy, Florida-based. Levy County Units 1 and 2 and Florida Power and Light's Turkey Point Units 6 and 7 [61]. The reactor units proposed are AP 1000 reactors by Westinghouse, with the net electrical power output of $1117 \mathrm{MW}^{\mathrm{b}}$. The construction of Virgil C. Summer units was canceled in 2017 while the other three proceeded with the construction. In this assessment, the FOAKE was also implied as a significant cost contributor for early plants. The full amount of FOAKE could be up to $35 \%$ of the overnight capital costs. The average OCs for an AP- 1000 reactor was estimated to be $\$ 4210 / \mathrm{kW}$. This figure falls between the Electric Power Research Institute's Technical Assessment Guide estimate of $\$ 4000 / \mathrm{kW}$ and DOE's Energy Information Administration 2011 estimate of $\$ 5339 / \mathrm{kW}$. There are many other incomparable figures quoted by reputable sources [62]. This clearly indicates the necessity of benchmarks for NPP's economic modeling.

In 2003, the U.S. DOE Nuclear Energy Research Advisory Committee and the Generation IV International Forum (GIF) jointly published a report identifying the need for economic-modeling benchmarks as one of the research priorities for the deployment of new-generation NPPs [62]. The Economic Modeling Working Group was formed in 2003 to develop economic models for future financial evaluations of Generation IV nuclear energy systems [51]. The GIF COA is a numerical system designed to provide cost components of projects starting from design, procurement, installation, and operation. It provides the DOE's cost-breakdown structure for all costs, including investment, O\&M, and fuel-cycle costs for different NPP technologies.

Table A-1 provides a high-level division of the capital cost based on GIF COA. Each high-level division has subcodes representing the cost components for each account. The one-digit code is further segregated into 2-digit codes. The detailed subdivisions of COA for the investment cost are listed in the Table A-2.

Table A-1.High-level COA division of the investment cost [51].

\begin{tabular}{|l|}
\hline Account 1-Capitalized Pre-Construction Costs \\
\hline Accounts 2-Capitalized Direct Costs \\
\hline Accounts 3-Field \& Field Management Indirect Costs \\
\hline Accounts 4-Capitalized Owner Operations \\
\hline Accounts 5-Capitalized Supplementary Costs \\
\hline Overnight Construction Cost \\
\hline Accounts 6-Capitalized Financial Costs \\
\hline Total Capital Investment Cost \\
\hline
\end{tabular}

b AP-1000 is a redesign of the previous AP-600 reactor. Its design certification effort was supported by DOE under the NP 2010 Program. The FOAKE cost was estimated at about $\$ 800$ million, of which $\$ 600$ million was incurred as part of the NP 2010 program and cost-shared by DOE. Vendor's share for FOAKE cost, about $\$ 500$ million, would be amortized in the cost of initial commercial deployments. 
Table A-2.Detailed COA for the investment cost [51].

\begin{tabular}{|c|c|}
\hline Account Number & Account Title \\
\hline 1 & Capitalized Pre-construction Costs \\
\hline 11 & Land and Land Rights \\
\hline 12 & Site Permits \\
\hline 13 & Plant Licensing \\
\hline 14 & Plant Permits \\
\hline 15 & Plant Studies \\
\hline 16 & Plant Reports \\
\hline 17 & Other Pre-construction Costs \\
\hline 18 & Other Pre-construction Costs \\
\hline 19 & Contingency - Pre-construction Costs \\
\hline 2 & Capitalized Direct Costs \\
\hline 21 & Structures and Improvements \\
\hline 22 & Reactor Equipment \\
\hline 23 & Turbine-Generator Equipment \\
\hline 24 & Electrical Equipment \\
\hline 25 & Heat Rejection System \\
\hline 26 & Miscellaneous Equipment \\
\hline 27 & Special Materials \\
\hline 28 & Simulator \\
\hline 29 & Contingency-Direct Costs \\
\hline \multicolumn{2}{|l|}{ DIRECT COST } \\
\hline 3 & Capitalized Support Services \\
\hline 31 & Field Indirect Costs \\
\hline 32 & Construction Supervision \\
\hline 33 & Commissioning and Start-up Costs \\
\hline 34 & Demonstration Test Run \\
\hline \multicolumn{2}{|c|}{ TOTAL FIELD COST } \\
\hline 35 & Design Services Offsite \\
\hline 36 & PM/CM Services Offsite \\
\hline 37 & Design Services Onsite \\
\hline 38 & PM/CM Services Onsite \\
\hline 39 & Contingency - Support Services \\
\hline \multicolumn{2}{|l|}{ BASE COST } \\
\hline 4 & Capitalized Operations \\
\hline 41 & Staff Recruitment and Training \\
\hline 42 & Staff Housing \\
\hline 43 & Staff Salary Related Costs \\
\hline 44 & Other Owner Capitalized Costs \\
\hline 49 & Contingency - Operations Costs \\
\hline 5 & Capitalized Supplementary Costs \\
\hline 51 & Shipping and Transportation Costs \\
\hline 52 & Spare Parts \\
\hline 53 & Taxes \\
\hline 54 & Insurance \\
\hline 55 & Initial Fuel Core Load \\
\hline 58 & Decommissioning Costs \\
\hline 59 & Contingency Supplementary Costs \\
\hline \multicolumn{2}{|l|}{$\mathrm{OC}$} \\
\hline 6 & Capitalized Operations \\
\hline 61 & Escalation \\
\hline
\end{tabular}


Generation 4 Excel-based Calculation of Nuclear Systems software uses the GIF COA for the economic assessment. Another tool, Nuclear Energy System Assessment Economic Support Tool (NEST) was developed by the International Atomic Energy Agency's (IAEA's) International Project on Innovative Nuclear Reactors and Fuel Cycles to enable a financial analysis. NEST is also an Excel-based evaluation tool. Reference [64] analyzes three different Generation IV nuclear energy systems - highperformance light-water reactor (LWR), break-even fast reactor, and burner fast reactor-to compare the financial figures in terms of the total capital investment cost (TCIC) and the levelized unit energy cost, evaluated using these two methodologies.

This detailed division of investment costs allows cost estimation using top-down or bottom-up techniques. A top-down cost-estimating approach is used for projects in their early life cycle when the budget for estimation and design is limited. In a top-down approach, cost estimation is accomplished by considering the cost of preexisting similar projects and scaling them upwards or downwards for the new system. On the other hand, the bottom-up approach requires rigorous investigation with detailed analysis of individual items, such as equipment, commodities, prices, and quantities. A complete project execution plan is needed to use this estimation approach. The activities are divided based on COA structures and can be highly detailed to 3-6 digit code. The highly detailed entries are then summed to two-digit levels to fit into EMWG's GIF COA model.

The deployment of SRs differs significantly from that of large NPPs. The increase in capital cost estimates of large NPPs in recent years is attributed to (1) price escalation on equipment and service for critical nuclear plant structures and components, (2) a better understanding of the cost components, and (3) increased dependence on fixed contracts and increased use of contingency costs to incorporate the uncertainty from various sources. Smaller nuclear plants, including SRs, could potentially mitigate the market risk experienced by large NPPs in several ways. They have lower project risk due to shorter construction schedules (24-36 months) and a smaller power footprint, resulting in less responsibility for selling power. Similarly, the modularity of SRs affords the flexibility to build incrementally the capacity per system need.

Due to the contrasting design and deployment approach with SRs, it is difficult to obtain the estimates for detailed cost components to fill the GIF COA shown in Table A-3. The cost models of SRs at present mostly rely on the vendor's cost targets or the scaled numbers from the cost of large reactors. Most vendors have not made their cost projections public, and the public ones are largely incomparable, mainly due to the incipient stage of the technology. All three leading SRs-Russia's KLT-40s, China's hightemperature gas-cooled reactor (HTGR), and Argentina's Central Argentina de Elementos Modulares (CAREM) - have faced significant cost overruns from their initial estimates [65]. Of these three leading SRs, the first plant, the Russian KLT-40s, consists of two 35 MW reactor units, the construction of which was recently completed, and cost $\$ 740$ million, or $\$ 10,570 / \mathrm{kW}$. China's pilot SR plant, the $210 \mathrm{MW}$ HTGR currently under construction, is expected to cost around $\$ 6000 / \mathrm{kW}$. Similarly, Argentina's $32 \mathrm{MW}$ CAREM-25 SR plant is expected to cost $\$ 700$ million or $\$ 21,875 / \mathrm{kW}$, based on 2017 estimates. In North America, NuScale SR is leading the SR development effort, with the first plant, a multi-module NuScale plant, to be built under Utah Associated Municipal Power Systems (UAMPS) carbon-free power project at the INL site by 2030. At the writing of this report (September 2021), UAMPS was evaluating options for the size of plant among 4-module, 6-module, 8-module, and 12-module configurations to ensure the most-economical energy supply to its members. With such support as production tax credits and DOE funding, the LCOE of the UAMPS NuScale plant is estimated to be \$66.30/MWh. Reference [52] reports the projected capital costs for a number of SR technologies around the world. Table A-3 lists the capital costs reported by various vendors for SRs of sizes close to the ones that are similar to the ones considered for this project [52][55]. 
Table A-3. Capital cost reported by different SR vendors.

\begin{tabular}{|c|c|c|c|}
\hline Reactor & Power Ratings (MW) & Capital Cost $(\$ / \mathbf{k W})$ & Coolant Type \\
\hline Elena (Russian) & 0.068 & 436000 & \multirow[t]{2}{*}{ Water Cooled } \\
\hline Unitherm (Russian) & 6.0 & 3048 & \\
\hline RAPID (Japan) & 1.0 & 8000 & Sodium Cooled \\
\hline KLT 20 (Russian) & 20.0 & 2500 & \\
\hline ABV (Russian) & 11.0 & 4300 & \\
\hline \multirow{3}{*}{$\begin{array}{l}\text { SPINNOR/VSPINNOR } \\
\text { (Indonesia) }\end{array}$} & 20.0 & 1500 & \multirow{3}{*}{$\begin{array}{l}\text { Lead Bismuth } \\
\text { Cooled }\end{array}$} \\
\hline & 10.0 & 1750 & \\
\hline & 6.35 & 2000 & \\
\hline MARS (Russian) & 6.0 & $2500-3500$ & Gas Cooled \\
\hline ABV (Russian) & 8.5 & 9100 & \\
\hline $\begin{array}{l}\text { Micro Modular Reactor } \\
\text { (Ultra-Safe Nuclear Corporation) }\end{array}$ & 5 & 15700 & Gas Cooled \\
\hline
\end{tabular}

Reference [66] provides the capital cost estimates for SRs quoted by other reputable sources, but not necessarily comparable units. It considers SR designs evolving from large reactor designs termed as evolutionary, high-technology-readiness-level (TRL) SRs and completely new designs, referred to as revolutionary, low-TRL SRs. For evolutionary FOAK SRs, the cost estimates were found in the range of $\$ 5274-12266 / \mathrm{kW}$. For evolutionary NOAK SRs, the vendor's estimates available are in the range of $\$ 2250-5960 / \mathrm{kW}$ whereas the estimates reported in the literature are in the range of $\$ 3970-16300 / \mathrm{kW}$. For revolutionary, low-TRL SRs, the cost estimates reported by vendors and in the literature are in the range of $\$ 1420-4588 / \mathrm{kW}$. The projected costs from vendors and the literature are uncertain and cannot be used for generic assessment for microgrid studies unless the reactor to be used is based on one of these.

Another approach is to estimate the cost from the experience with NPP projects in past. The widely used Equation (1) reflects the economy of scale to estimate the OC of smaller plants by scaling down from the OC of large NPPs [67]-[71].

$O C_{S R}=O C_{l N P P} *\left(\frac{M W_{S R}}{M W_{l N P P}}\right)^{n}$

where $n=0.4$ to 0.6 is the scaling factor. This scaling factor results in the total OC of small NPPs in dollars, based on economy of scale. The OC estimate is highly sensitive to the scaling factor, which is obtained by statistically fitting the cost of past NPPs.

Once the capital cost is scaled based on size, further reduction is applied based on the economic advantages offered by SRs compared to large NPPs. Such cost models require particular focus on several cost-saving parameters, such as (1) factory mass production, (2) shorter construction schedule (3) accelerated learning, (4) simpler design, and (5) inherent/passive safety, possibly resulting in reduced regulatory burden (Figure A-2). 


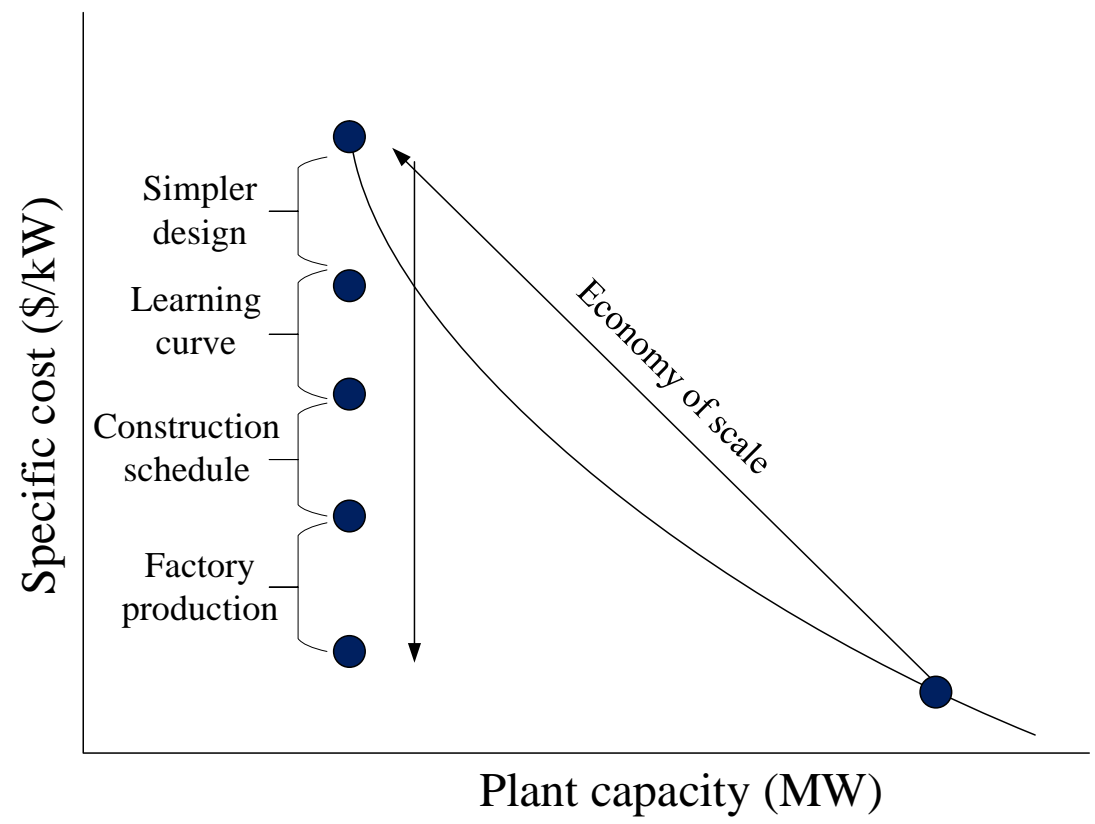

Figure A-2. Factors to be considered while scaling down investment cost from large reactors.

Current economic-modeling efforts, such as in [8] and [72], discuss the role of these factors for SRs' feasible deployment. Reference [73] estimates the best achievable OC for a NOAK SR plant to be $\$ 4700 / \mathrm{kW}$. With factory-produced modules, a learning rate of $10 \%$ is considered. This means that the estimated cost of the reactor module can be reasonably reduced by $10 \%$ for every doubling of the number of modules. The $10 \%$ learning rate is the same used by Navy shipbuilding programs. Four different project scenarios are considered: Lead/2, Lead, FOAK, and NOAK. The lead plant represents the first-ofa-kind of custom-built SR plant that would be produced in a factory in the future. The lead plant proposed was a $600 \mathrm{MW}$ NPP, with six $100 \mathrm{MW}$ modules. The OC of the lead plant is estimated in the range of $\$ 7000-11500 / \mathrm{kW}$. Lead/2 would be half the scale of lead plants, with three $100 \mathrm{MW}$ modules. Although the specific capital cost (i.e., $\$ / \mathrm{kW}$ cost) may be even larger for half-scaled plants, the Lead/2 deployment as an initial SR commercial plant would reduce the total capital cost of initial plants. Sensitivity analysis shows that the LCOE of the SR plant can be competitive with that of natural gas combined-cycle plants after the deployment of 18 or more modules. The study concluded that an incentivized learning period would be necessary to improve the cost-competitiveness of SRs over time. The government incentives were to be necessary for lead and FOAK plants if they were to compete in an energy market with naturalgas-fired plants. Further, the SR's cost-effectiveness would benefit if regional or technology-specific market opportunities are properly identified. Considering their site flexibility, SRs would be suitable for locations where other forms of generation are not feasible - for example, in remote locations with limited wind and solar resources and limited access to transportation for importing biomass fuels. These would be ideal sites for lead or FOAK SR plants.

Reference [8] used a similar cost-estimation approach by scaling down from the cost of large reactors, while preserving the economy of scale, and then applying the cost-saving factors with modular design, co-siting, learning, and design simplification. Detailed expressions representing the calculations of each of the factors were also reported. The OC obtained from this scaling approach further needs to consider the interest during the construction period. The capital cost for the first SR plant of a $180 \mathrm{MW}$ reactor unit is estimated as $\$ 4625 / \mathrm{kW}$ for a multimodule plant with seven units and $\$ 8973 / \mathrm{kW}$ for a single-module plant. The estimate for NOAK plants was $\$ 4173 / \mathrm{kW}$ for a multimodule plant and $\$ 5535 / \mathrm{kW}$ for a singlemodule plant. The case for very-small-modular reactors was analyzed for deployment in remote parts of 
Alaska. For a 5 MW plant, the FOAK was estimated to cost between $\$ 47523$ and $\$ 64031 / \mathrm{kW}$; a NOAK plant, between $\$ 35678$ and $\$ 48072 / \mathrm{kW}$.

Reference [68] provided a systematic review of reports and publications, focused on studies related to SR economics. The review focused on answering two major questions: what we know and what we don't know. It attempted to describe current progress on financial modeling and analysis of SRs. The analysis of capital cost included the loss of economy of scale and cost savings via increased learning rate, shorter construction schedule, design simplification, and extended fuel cycle. Based on the various reports analyzed in [68], the loss of economy of scale due to smaller size was estimated to cost SRs 70\% more in terms of capital cost. But the cost savings of $14 \%$ due to co-siting of multiple units, $8 \%$ due to learning, $6 \%$ due to smaller construction schedule, and $17 \%$ due to design resulted in capital costs of SRs being only 5\% higher than large NPPs. Similarly, [74] estimated the base construction cost of NuScale $(\$ 3465.72 / \mathrm{kW})$ to be $37 \%$ less than a PWR-12 plant $(\$ 5587.12 / \mathrm{kW})$. Reference [70] added one additional factor of unit timing, which refers to the gradual addition of SR modules with time and according to need. The savings with unit timing was considered 5\%, with combined learning and co-siting $22 \%$, construction schedule 5\%, and plant design 5\%.

The use of Equation (1) to scale large reactors may work for medium-sized reactors, but for SRs of size 0.1-20 MW, the errors are too large. Reference [66] excludes the economy-of-scale technology factor from the cost estimation assuming the SR designs are novel and optimized for a smaller scale. The economy-of-scale development factor, however, is included, assuming that the development cost will not vary with the size of SRs. SR studies focused on on-grid and off-grid deployment in Canada considered the cost savings in SRs via co-siting and design improvement and included the off-grid cost penalty for the SRs to be hosted in off-grid locations.

Clearly, a new approach is necessary to estimate the capital costs of SRs. Another approach seen in [56] shows the scaling of various underlying cost components, instead of the total OC. While it may be difficult to get suitable cost factors for each cost component, it would allow more flexibility to implement the contrasting characteristics of SRs with respect to large reactors in cost estimation. With the process focused on the estimation of cost components instead of the total cost, researchers and engineers would be able to use their judgment in estimating values.

\section{A-1.2 O\&M Costs}

O\&M costs represent the second-largest part of the NPP life-cycle cost. In general, it includes the expenses for staff, the back-end and front-end fuel cost, and the expenses for planned and unplanned maintenance of the plant. Like capital costs, the O\&M cost is difficult to estimate correctly for SRs because the first plant has yet to go into operation. While of equal importance with capital costs in an investigation of economic feasibility, the O\&M costs of SRs have not received much-needed research attention [51]. A better understanding of O\&M cost is one of the priorities for cost modeling research of new generation NPPs. Table A-4. lists the GIF's COA representing the cost components of O\&M costs. 
Table A-4. COA divisions of O\&M cost [51].

\begin{tabular}{|l|l|}
\hline $\begin{array}{c}\text { Account } \\
\text { Number }\end{array}$ & \multicolumn{1}{c|}{ Account Title } \\
\hline 7 & Annual O\&M Cost \\
\hline 71 & O\&M staff \\
\hline 72 & Management Staff \\
\hline 73 & Salary Related Costs \\
\hline 74 & Operations Chemicals and Lubricants \\
\hline 75 & Spare Parts \\
\hline 76 & Utilities, Supplies, Consumables \\
\hline 77 & Capital Plant Upgrades \\
\hline 78 & Taxes and Insurance \\
\hline 79 & Contingency Annualized O \& M Costs \\
\hline 8 & Annualized Fuel Cost \\
\hline 81 & Refueling operations \\
\hline 84 & Nuclear Fuel \\
\hline 86 & Fuel reprocessing Charges \\
\hline 89 & Annualized Fuel Costs \\
\hline 9 & Annualized Financial Costs \\
\hline 91 & Escalation \\
\hline 92 & Fees \\
\hline 93 & Cost of Money \\
\hline 99 & Contingency Annualized Financial Costs \\
\hline
\end{tabular}

Even for larger reactors, the O\&M cost has not been certain and depends upon various factors, including reactor technology, age of the plant, and cost escalation. Reference [56] reports a considerable spread in O\&M costs, varying between $\$ 16.9$ and $\$ 25.8 / \mathrm{MWh}$. In the case of SRs, only a few directly reported O\&M costs. We were able to find only two SR vendors that disclosed their O\&M cost targets. HTR-PM, a 105 MW SR, projects the O\&M cost as \$21/MWh while the 285 MW GT-MHR aims at \$13/MWh [56].

Reference [75] predicts that O\&M for SRs is higher than for advanced LWRs. Although regulatory requirements are not yet clear, the cost for staff per unit of energy produced in smaller plants is expected to be larger than in large NPPs. Long durations between refueling helps in cost saving for SRs that have this feature via reduced fuel cost and outage duration. In the case of multiunit plants, the staffing cost could be reduced by shared control of reactor units. Furthermore, the reduction in outage duration by coordinated maintenance allows cost saving through reduced outages. One important factor to be considered and analyzed would be the cost of flexible operation for SRs hosted with intermittent renewables or in isolated microgrids. The non-baseload operation is expected to result in inefficient fuel use and further need of maintenance due to increased operation of moving parts, such as valves.

A review paper [68] quantifies the impact of various factors on SR's O\&M costs. SR O\&M costs are expected to be higher than those of large NPPs. If the size factor alone is considered, SR's O\&M costs may be expected to be $51 \%$ greater than large NPPs. Considering cost reduction determined by multiple units at single sites (15\%), additional outage cost (3\%), and outage duration (4\%), SR O\&M costs are 
19\% higher [67]. References [67] and [68] highlight that the main reason for this is the loss of the economy of scale. Co-siting economies might reduce the fixed O\&M costs by 10-20\%, and operational learning (determined through familiarity with the designs and consistency of operations) might further reduce the variable O\&M costs (potential saving of 5\%). Reference [75] estimates the O\&M cost of SRs in the range of $\$ 40-90 / \mathrm{MWh}$ while [56] estimates it to vary between $\$ 7.1$ and $\$ 36.2 / \mathrm{MWh}$.

\section{A-1.3 Fuel-Cycle Cost}

One of the major advantages of nuclear plants over coal- and gas-fired plants has been low fuel costs. The U.S. Nuclear Energy Institute suggests that the cost of fuel for a coal-fired plant is $78 \%$ of total costs; for a gas-fired plant, the figure is $87 \%$. For nuclear, the uranium is about $14 \%$ (or $34 \%$ if all front-end and waste-management costs are included). The nuclear fuel cycle consists of events starting from the production of fuel up to its disposal. The GIF's COA representing the fuel-cycle cost in a nuclear power plant are listed in Table A-5.

Table A-5. COA divisions of the fuel cycle cost [50].

\begin{tabular}{|c|l|}
\hline $\begin{array}{c}\text { Account } \\
\text { Number }\end{array}$ & \\
\hline $10 \mathrm{X}$ & Fuel assembly supply, first core (covered as Account 55 in capital cost) \\
\hline 101 & $1^{\text {st }}$ Core Uranium supply \\
\hline 102 & $1^{\text {st }}$ Core Conversion \\
\hline 103 & $1^{\text {st }}$ Core Enrichment \\
\hline 104 & $1^{\text {st }}$ Core Fuel assembly fabrication \\
\hline 105 & $1^{\text {st }}$ Core Supply of other fissionable materials \\
\hline $11 \mathrm{X}$ & Services, first core \\
\hline 111 & Fuel management (U, Pu, Th) (ignore for early estimates) \\
\hline 112 & Fuel management schedule (ignore for early estimates) \\
\hline 113 & Licensing assistance (ignore for early estimates) \\
\hline 114 & Preparation of computer programs (ignore for early estimates) \\
\hline 115 & Quality assurance (embed in fuel fabrication cost, Account 554) \\
\hline 116 & Fuel assembly inspection (embed in fuel fabrication cost, Account 554) \\
\hline 117 & Fuel assembly intermediate storage (embed in fuel fabrication. cost, Account 554) \\
\hline 118 & Information for the use of third-party fuel (ignore for early estimates) \\
\hline $12 \mathrm{X}$ & Fuel assembly supply for reloads (calculate as equilibrium reloads and annualize costs) \\
\hline 121 & Uranium supply for reloads \\
\hline 122 & Conversion for reloads \\
\hline 123 & Enrichment for reloads \\
\hline 124 & Fuel assembly fabrication for reloads \\
\hline 125 & Supply of other fissionable materials for reloads \\
\hline $13 \mathrm{X}$ & Services, reloads \\
\hline 131 & Fuel management (ignore for early estimates) \\
\hline 132 & Fuel management, schedule (ignore for early estimates) \\
\hline 133 & Licensing assistance (ignore for early estimates) \\
\hline 134 & Preparation of computer programs (ignore for early estimates) \\
\hline 135 & Quality assurance (embed in Account 124) \\
\hline 136 & Fuel assembly inspection (embed in Account 124) \\
\hline 137 & Fuel assembly intermediate storage (embed in Account 124) \\
\hline 138 & Information for the use of third-party fuel (embed in Account 124) \\
\hline 140 & Reprocessing of irradiated fuel assemblies \\
\hline 141 & Credits for uranium, plutonium, and other materials \\
\hline 142 & Final disposal of fuel assemblies (in the case of no reprocessing) \\
\hline 143 & Final waste disposal \\
\hline & \\
\hline
\end{tabular}




\begin{tabular}{|l|l|}
\hline $\begin{array}{l}\text { Account } \\
\text { Number }\end{array}$ & \multicolumn{1}{c|}{ Account Title } \\
\hline 150 & Heavy water supply, first charge (include in TCIC Account 27) \\
\hline 151 & Heavy water services, first charge (include in TCIC Account 27) \\
\hline 160 & Heavy water supply, replacement quantities (include in O\&M Account 810) \\
\hline 161 & Heavy water services, replacement quantities (include in O\&M Account 810) \\
\hline 170 & Financial costs of the nuclear fuel cycle (ignore for early estimates) \\
\hline 171 & Financial costs of heavy water (ignore for early estimates) \\
\hline
\end{tabular}

The initial investment in a plant includes the front-end cost of the fuel for first loading. Similarly, the decommissioning cost includes the back-end of fuel cost for the last fuel loading of the nuclear plant. The remainder of the front-end and back-end fuel costs are annualized as O\&M costs of the plant.

The front end of fuel cost represents the price of fuel loading to the reactor core. Naturally extracted uranium ores are milled to produce uranium-ore concentrate or yellowcake $\left(\mathrm{U}_{3} \mathrm{O}_{8}\right)$. The uranium-ore concentrate then goes through several stages to generate the nuclear fuel (typically $\mathrm{UO}_{2}$ ) that is used in the reactor core. In general, the overall steps can be divided into three stages: conversion, enrichment, and fabrication. The conversion process produces uranium hexafluoride $\left(\mathrm{UF}_{6}\right)$ from the uranium-ore concentrate. Enrichment increases the concentration of uranium-235 in $\mathrm{UF}_{6}$. Fuel fabrication then converts the enriched $\mathrm{UF}_{6}$ into $\mathrm{UO}_{2}$ to be included in the reactor core. Table A- 6 provides the recent pricing on different stages of the front-end fuel cycle as reported by World Nuclear Association.

Table A-6. Front-end fuel-cycle pricing of $\mathrm{UO}_{2}$ fuel [54].

\begin{tabular}{|l|l|l|l|}
\hline Process & Amount Required $\times$ Price & Cost & Proportion of Fuel \\
\hline Uranium & $8.9 \mathrm{~kg} \mathrm{U} \mathrm{O}_{8} \times \$ 68$ & $\$ 605$ & $43 \%$ \\
\hline Conversion & $7.5 \mathrm{~kg} \mathrm{U} \times \$ 14$ & $\$ 105$ & $8 \%$ \\
\hline Enrichment & $7.3 \mathrm{SWU} \times \$ 52$ & $\$ 380$ & $27 \%$ \\
\hline Fuel Fabrication & per kg & $\$ 300$ & $22 \%$ \\
\hline Total & & $\mathbf{\$ 1 , 3 9 0}$ & \\
\hline
\end{tabular}

The back end of the fuel cycle involves removing spent fuel from the reactor vessel, interim storage, and final disposal. The spent fuels can either be reprocessed or be directly disposed of. Reprocessing is an expensive option and is not economical unless the cost of producing new fuel is very high [59][76]. Reference [59] reports that the back end of the fuel cycle sums to $10 \%$ of the overall costs, or less if there is a direct-disposal option instead of reprocessing.

Once loaded, the fuel in the reactor core can last for several years. For SRs, the refueling time is expected to be 5 years or more [55]. In a Toshiba-CRIEPI (4s) reactor, the refueling time is proposed to be 30 years [5]. The longer refueling interval certainly helps to bring down fuel cycle costs in SRs. Similarly, another important factor that could have a major impact is fuel burnup, also known as fuel utilization. It is the measure of how much energy is extracted from nuclear fuel. In older NPPs, the burnup rate was designed to be in the range of 35-40 GWd/tU. Currently, with improved fuel technology, burnup rates higher than $60 \mathrm{GWd} / \mathrm{tU}$ can be obtained [77].

\section{A-1.4 Waste Handling and Decommissioning}

Waste-handling costs include the back end of the fuel cost and the cost required for the disposition of spent fuel after interim storage. Reprocessing allows the recycling of unused uranium and plutonium in the form of reprocessed uranium oxide or mixed-oxide fuel [59]. Reprocessing plants use large amounts of chemicals. Different subsidiary facilities are needed for a reprocessing plant, including a recycled-fuel fabrication unit, a vitrification unit, a waste-conditioning unit, with a final repository for high-level waste. 
On the other hand, direct disposal requires an interim storage facility, an encapsulation facility to prepare waste fuel bundles for disposal, and a DGR for final disposal [76]. The cost of reprocessing can be estimated by using the unit prices for each stage. The waste-handling cost reported in [71] is shown below in Table A-7.

Table A-7. Used fuel disposal steps and costs.

\begin{tabular}{|l|l|}
\hline Process Step & Unit Cost $\mathbf{( \$ \mathbf { k g H M } )}$ \\
\hline Wet Storage & 331 \\
\hline Dry Storage & 113 \\
\hline Waste Conditioning & 110 \\
\hline Transportation & 125 \\
\hline DGR & 718 \\
\hline Total & $\mathbf{1 3 9 7}$ \\
\hline
\end{tabular}

KgHM: kilogram heavy metals

Based on the Nuclear Waste Policy Act, the owners of spent nuclear fuel are required to pay a fee of $\$ 1$ for each MWh of electricity generated. The fund is aimed at creating a permanent repository for nuclear waste.

Newer nuclear plants, including SRs, are designed with lifetimes on the order of 40-60 years. At the end of their lives the plants are demolished, and then are cleaned to make the plant site available for other applications. Until now, more than 180 experimental, commercial, or prototypical reactors, and over 500 research reactors, have been retired, and some of these are dismantled. The IAEA has defined three options for decommissioning: immediate dismantling, which usually begins within a few months after the end of life; deferred dismantling, where the decontamination and demolition are postponed for 40-60 years to allow residual reactivity to decay; and entombment, which refers to enclaving the site with concrete materials and never dismantling the facility. Decommissioning costs are about $9-15 \%$ of the initial capital cost for a nuclear power plant. But when discounted over the lifetime of the plant, they contribute only a few percent to the investment cost and even less to the generation cost. In the U.S., they account for $0.1-0.2$ cents $/ \mathrm{kWh}$, which is no more than $5 \%$ of the cost of the electricity produced [54].

\section{A-2. FLEXIBLE OPERATION AND RAMP RATES}

SRs are designed to operate more flexibly in variable-power system conditions than conventional NPPs. Conventional NPPs in North America are operated predominantly as baseload plants. The European NPPs, however, have been operating in flexible modes for more than a decade now [47]. Although the flexible operation capabilities of SRs are not disclosed by the vendors, the experience with European NPPs is used to estimate the capabilities for SRs.

Conventional NPPs in Europe are used for primary frequency regulation at ramp rates up to 60\% rated electrical output (REO)/min, which is within their design limits [47][49]. Similarly, a recent Russian reactor model, VVER-1200/V-491, under AES-2006, demonstrates the 5\% REO of power change in frequency regulation mode with ramp rates of $60 \% \mathrm{REO} / \mathrm{min}$. The reactor module is capable of fast power modulation of $5 \% \mathrm{REO} / \mathrm{s}(300 \% \mathrm{REO} / \mathrm{min})$ for up to $10 \% \mathrm{REO}$ power change without any impact on the fatigue strength of the equipment. While the net power change for frequency regulation is generally small, it could be large for load-following operations. Therefore, under the load-following mode, NPPs are controlled to a certain number of power cycles, depending on the stipulated design limits provided by the manufacturer to avoid any excessive thermal stress on the components. The previously mentioned VVER-1200/V-392 reactor has a design capability of 20,000 power cycles over a lifetime for planned and unplanned load following with variation of up to $\pm 50 \%$ REO, with maximum ramp rates of $20 \% \mathrm{REO} / \mathrm{min}$ [49]. 
Flexible operation through control-rod maneuvering comes with its own sets of problems. Due to the increased flexible operation with large and frequent thermal cyclic loadings, thermal fatigue is aggravated for most reactor structures, systems, and components [47]. The aging of active components like controlrod drives, valves, pumps, nozzles and pipes also hastens due to increased flexible operation. Operational systems, such as valves, face additional erosion and corrosion due to their frequent operation in response to demand variations. Even though thermal and hydraulic variations have only secondary effects on erosion or corrosion of primary side components, the increased concentration of chemical impurities due to flexible operation could aggravate the corrosion rates of reactor coolant pump seals and steamgenerator tubes. The use of boric acid as a neutron absorber for flexible operation changes the $\mathrm{pH}$ value and lithium concentration of the coolant, potentially resulting in the activation of corrosion products. The operation of control rods causes core power redistribution, thus affecting the power densities in the core, which could have a significant impact on fuel safety limits. Similarly, reactor power variation influences the thermal expansion of the fuel pallets, imposing pellet/cladding hard contacts, which could result in cracks and mechanical failure of the cladding. This cladding stress is proportional to local power density, which is affected by the operation of the control rod. The frequent operation of a control rod could also induce shadow corrosion, which could distort the channels and ultimately cause hard contact between core components and the supports.

Reactor thermal-power control dynamics are also challenged by the counter-reactions from fuel and moderator temperatures [49]. The temperature variation in the primary circuit results in a change in coolant density, hence changing the boric acid concentration and making power control even more difficult. Fission-product poisoning is another factor that adds challenge to reactor control. Xenon-135 is a strong neutron absorber that is produced during the fission of heavy nuclei. Another fission product, iodine-135, also decays to xenon-135 in 6-7 hours. The variation of negative reactivity due to xenon-135 thus lasts for several hours of power variation, which poses a significant challenge for reactor-power control. Further, the variation of axial distribution of xenon-135 with control-rod movement also aggravates the problem.

Modern SRs are designed with additional schemes other than traditional control-rod maneuvering to provide flexible operation [78]. The power management under NuFollow postulates three different options for flexible operations - taking one or more modules offline for extended periods of low grid demand, maneuvering reactor power for one or more modules for demand variations, and bypassing the steam turbine to compensate for rapid changes in response to the turbine-valve operation [78].

Taking modules out of service is only applicable to multimodule plants, and even so, such a scheme would only be useful to meet long-term demand variations. Reactor maneuvering is also limited to coarse load shaping of the electrical demand. Bypassing the steam directly to the condenser can offer immediate response, as for frequency control. However, bypassing steam to the condenser, in addition to not being economical, can result in additional wear and tear on the condenser shell and tubes, steam-bypass lines, and the associated valves. A better alternative would be to use the bypassed steam for secondary heat applications. In modern systems, the use of electrical and thermal energy storage can offer possibilities for flexible operation for NPPs without impacting reactor safety.

Reference [48] determines the flexible operation capabilities needed of SRs based on their target applications. Considering the case for deploying SRs alongside intermittent renewables in remote communities, the required flexible operation capabilities were determined. Three different operating limits were proposed for the SRs to be deployed in remote communities: Basic, Advanced and Extreme (Figure A-3). 


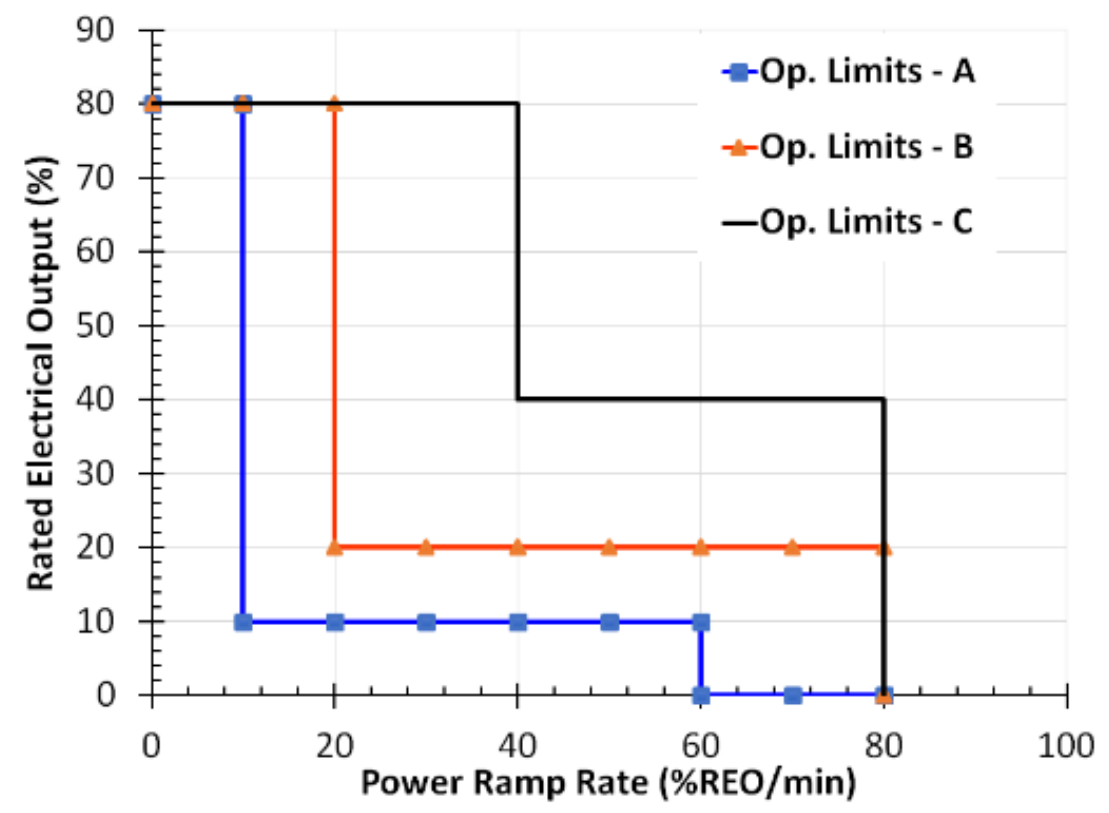

Figure A-3. Limits proposed for SRs in [47]: Basic (A), Advanced (B) and Extreme (C). 
Page intentionally left blank 


\section{Annex B \\ List of Small Modular Reactor (SMR) and Microreactor Concepts Potentially Suitable for Microgrid Applications}


Page intentionally left blank 


\section{Annex B \\ List of Small Modular Reactor (SMR) and Microreactor Concepts Potentially Suitable for Microgrid Applications}

Table B-1. SMR and microreactor concepts potentially suitable for microgrid applications.

\begin{tabular}{|c|c|c|c|c|c|c|}
\hline Reactor & $\begin{array}{l}\text { Principle } \\
\text { Designer }\end{array}$ & Technology & $\begin{array}{l}\text { Rating } \\
\text { (MW/ } \\
\text { MWt) }\end{array}$ & $\begin{array}{l}\text { Core } \\
\text { Life/ } \\
\text { Plant } \\
\text { Life } \\
(\mathrm{yr}) \\
\end{array}$ & Status & Target Application \\
\hline MARVEL & $\begin{array}{l}\text { Idaho National } \\
\text { Laboratory } \\
\text { (INL) }\end{array}$ & $\begin{array}{l}\text { Sodium- } \\
\text { cooled } \\
\text { reactor } \\
\text { with } \\
\text { with TRIGA } \\
\text { fuel }\end{array}$ & $0.02 / 0.1$ & $2 /-$ & $\begin{array}{l}\text { Conceptual } \\
\text { Design }\end{array}$ & $\begin{array}{l}\text { Microreactor } \\
\text { demonstration }\end{array}$ \\
\hline Micro Modular Reactor & $\begin{array}{l}\text { Ultra-Safe } \\
\text { Nuclear } \\
\text { Corporation }\end{array}$ & $\begin{array}{l}\text { High } \\
\text { Temperature } \\
\text { Gas-cooled } \\
\text { Reactor / } \\
\text { micro- } \\
\text { reactor / } \\
\text { nuclear } \\
\text { battery } \\
\end{array}$ & $5 / 15$ & $20 / 20$ & $\begin{array}{l}\text { Conceptual } \\
\text { Design }\end{array}$ & $\begin{array}{l}\text { Remote communities; } \\
\text { Heavy industry } \\
\text { application; } \\
\text { Standalone microgrid; } \\
\text { Process heat and } \\
\text { hydrogen production }\end{array}$ \\
\hline Elena & $\begin{array}{l}\text { National } \\
\text { Research } \\
\text { Centre } \\
\text { "Kurchatov } \\
\text { Institute", } \\
\text { Russia }\end{array}$ & $\begin{array}{l}\text { Pressurized } \\
\text { Water } \\
\text { Reactor } \\
\text { (PWR) }\end{array}$ & $0.068 / 3.3$ & $25 /-$ & $\begin{array}{l}\text { Conceptual } \\
\text { Design }\end{array}$ & Commercial facilities \\
\hline $\begin{array}{l}\text { Unitherm } \\
+\end{array}$ & $\begin{array}{l}\text { N.A. Dollezhal } \\
\text { Scientific } \\
\text { Research and } \\
\text { Design } \\
\text { Institute of } \\
\text { Energy } \\
\text { Technologies, } \\
\text { Russian } \\
\text { Federation }\end{array}$ & PWR & $6.0 / 30.0$ & $\begin{array}{l}20- \\
25 / 30\end{array}$ & $\begin{array}{l}\text { Conceptual } \\
\text { Design }\end{array}$ & $\begin{array}{l}\text { Electricity; District } \\
\text { heating; } \\
\text { Potable water }\end{array}$ \\
\hline 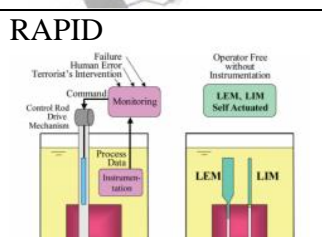 & $\begin{array}{l}\text { Central } \\
\text { Research } \\
\text { Institute of } \\
\text { Electrical } \\
\text { Power } \\
\text { Industry, Japan }\end{array}$ & $\begin{array}{l}\text { Sodium } \\
\text { Cooled }\end{array}$ & $1.0 / 10.0$ & $10 /-$ & $\begin{array}{l}\text { Conceptual } \\
\text { Design }\end{array}$ & $\begin{array}{l}\text { Electricity; Potable } \\
\text { water; Powerhouse for } \\
\text { colonies on the Moon } \\
\text { and Mars }\end{array}$ \\
\hline
\end{tabular}




\begin{tabular}{|c|c|c|c|c|c|c|}
\hline PSRD & $\begin{array}{l}\text { Japan Atomic } \\
\text { Energy } \\
\text { Agency, Japan }\end{array}$ & $\begin{array}{l}\text { Integral } \\
\text { PWR }\end{array}$ & $31.0 / 100$ & $>5 /-$ & $\begin{array}{l}\text { Conceptual } \\
\text { Design }\end{array}$ & Electricity \\
\hline KLT-40 & $\begin{array}{l}\text { JSC } \\
\text { "Afrikantov } \\
\text { OKBM", } \\
\text { Rosatom, } \\
\text { Russian } \\
\text { Federation }\end{array}$ & $\begin{array}{l}\text { PWR in } \\
\text { Floating } \\
\text { Nuclear } \\
\text { Power Plant } \\
\text { (FNPP) }\end{array}$ & $50 / 175$ & $10 / 60$ & In Operation & $\begin{array}{l}\text { Electricity; } \\
\text { Seawater desalination; } \\
\text { Sea oil-production }\end{array}$ \\
\hline & $\begin{array}{l}\text { JSC } \\
\text { "Afrikantov } \\
\text { OKBM", } \\
\text { Rosatom, } \\
\text { Russian } \\
\text { Federation }\end{array}$ & $\begin{array}{l}\text { PWR in } \\
\text { FNPP }\end{array}$ & $6-9 / 38$ & $\begin{array}{l}10- \\
12 / 40\end{array}$ & Final Design & $\begin{array}{l}\text { Electricity; District } \\
\text { heating; } \\
\text { Potable water }\end{array}$ \\
\hline $\begin{array}{l}\text { RDE/Micro-PeLUIt } \\
=\end{array}$ & $\begin{array}{l}\text { National } \\
\text { Nuclear } \\
\text { Energy } \\
\text { Agency, } \\
\text { Indonesia }\end{array}$ & $\begin{array}{l}\text { Pebble bed } \\
\text { HTGR. }\end{array}$ & $3 / 10$ & $-/ 40$ & $\begin{array}{l}\text { Site license } \\
\text { issued. } \\
\text { Design } \\
\text { Approval } \\
\text { phase. }\end{array}$ & $\begin{array}{l}\text { Research reactor; } \\
\text { Scaled up for } \\
\text { commercial application }\end{array}$ \\
\hline \multirow[t]{2}{*}{$\begin{array}{l}\text { NuScale Micro- } \\
\text { Reactors }\end{array}$} & \multirow[t]{2}{*}{ NuScale, } & $\begin{array}{l}\text { Integral } \\
\text { PWR } \\
\text { (Micro- } \\
\text { NuScale } \\
\text { Power } \\
\text { Module) }\end{array}$ & $10-50 /-$ & $-1-$ & Concept & $\begin{array}{l}\text { Small grids; Remote } \\
\text { communities; Off-grid } \\
\text { industrial and } \\
\text { commercial facilities; } \\
\text { Remote mining; } \\
\text { military installations }\end{array}$ \\
\hline & & $\begin{array}{l}\text { Heat Pipe } \\
\text { Reactor }\end{array}$ & 1-10/- & $-/-$ & Concept & $\begin{array}{l}\text { Remote off-grid } \\
\text { communities with } \\
\text { seasonal fuel delivery } \\
\text { limitations; Remote } \\
\text { mining; Disaster relief; } \\
\text { Space applications }\end{array}$ \\
\hline Aurora & $\begin{array}{l}\text { Oklo Power } \\
\text { LLC }\end{array}$ & $\begin{array}{l}\text { Fission } \\
\text { battery, fast } \\
\text { spectrum }\end{array}$ & $1.5 / 4$ & $20 / 20$ & $\begin{array}{l}\text { Conceptual } \\
\text { Design }\end{array}$ & $\begin{array}{l}\text { Fuel-recycle; } \\
\text { Microgrids }\end{array}$ \\
\hline eVinci & $\begin{array}{l}\text { Westinghouse } \\
\text { Electric } \\
\text { Corporation }\end{array}$ & $\begin{array}{l}\text { Heat Pipe } \\
\text { Reactor }\end{array}$ & $\begin{array}{l}2-3.5 / 7- \\
12\end{array}$ & $3+/ 40$ & $\begin{array}{l}\text { Conceptual } \\
\text { Design }\end{array}$ & $\begin{array}{l}\text { Remote communities; } \\
\text { Mining; District heating }\end{array}$ \\
\hline \multirow[t]{3}{*}{ SPINNOR/VSPINNOR } & \multirow[t]{3}{*}{ Indonesia } & \multirow{3}{*}{$\begin{array}{l}\text { Lead } \\
\text { Bismuth } \\
\text { Cooled }\end{array}$} & $20.0 / 55.0$ & $15 /-$ & \multirow{3}{*}{$\begin{array}{l}\text { Feasibility } \\
\text { Study }\end{array}$} & \\
\hline & & & $10.0 / 27.5$ & $25 /-$ & & \\
\hline & & & $6.35 / 17.5$ & $35 /-$ & & \\
\hline Package Reactor & $\begin{array}{l}\text { Hitachi, Ltd. } \\
\text { and Mitsubishi } \\
\text { Heavy }\end{array}$ & $\begin{array}{l}\text { Boiling } \\
\text { Water } \\
\text { Reactor }\end{array}$ & $\begin{array}{l}\text { Variable/ } \\
(10-100)\end{array}$ & $\begin{array}{l}5 \text { to } \\
10 /-\end{array}$ & $\begin{array}{l}\text { Conceptual } \\
\text { design }\end{array}$ & Electricity \\
\hline
\end{tabular}




\begin{tabular}{|c|c|c|c|c|c|c|}
\hline & $\begin{array}{l}\text { Industries, } \\
\text { Japan }\end{array}$ & $\begin{array}{l}\text { (BWR); } \\
\text { PWR }\end{array}$ & & & & \\
\hline CHTR & $\begin{array}{l}\text { Bhabha } \\
\text { Atomic } \\
\text { Research } \\
\text { Centre, India }\end{array}$ & Gas Cooled & $0.023 / 0.1$ & $15.1 /-$ & $\begin{array}{l}\text { Conceptual } \\
\text { Design }\end{array}$ & $\begin{array}{l}\text { Electricity; Hydrogen; } \\
\text { Potable water }\end{array}$ \\
\hline MARS & $\begin{array}{l}\text { RRC } \\
\text { "Kurchatov } \\
\text { Institute", } \\
\text { Russian } \\
\text { Federation }\end{array}$ & $\begin{array}{l}\text { Non- } \\
\text { conventional }\end{array}$ & $6.0 / 16$ & $15 / 60$ & $\begin{array}{l}\text { Conceptual } \\
\text { Design }\end{array}$ & $\begin{array}{l}\text { Electricity; High } \\
\text { temperature process } \\
\text { heat; District heating; } \\
\text { Potable water }\end{array}$ \\
\hline
\end{tabular}


Page intentionally left blank 


\section{Annex C \\ Net-Zero Microgrid Program}


Page intentionally left blank 


\section{Annex C \\ Net-Zero Microgrid Program}

The Net-Zero Microgrid (NZM) Program seeks to produce the cross-cutting research needed to support the accelerated removal of carbon-emitting generation from microgrids. Microgrids do and will increasingly function in many key roles in the security and resilience of critical loads, electrification of infrastructure, and support for distribution and the bulk electric grid. A reduction in the carbon footprint of microgrid designs is imperative to achieving GHG reduction goals in the drive towards a net-zerocarbon economy for the U.S.

The NZM program, supported by the DOE-OE, organizes research and development activities across multiple energy resources deployed in microgrids. The program leverages the expertise and platforms established by the programs across DOE offices. The program will use the renewable integration microgrid in the Energy Systems Laboratory and small nuclear reactor research testbeds like the Microreactor Applications Research Validation and Evaluation (MARVEL) demonstration microreactor located at the TREAT Facility at Idaho National Laboratory.

The NZM program at INL provides a clear structure for coordination with the DOE-OE to manage the technical direction, activities, and milestones for achieving net-zero goals for microgrids.

This report leads directly to the recognition of SRs as zero-carbon generation in microgrids as one of the ultimate goals of NZM program initiatives to:

- Develop requirements for the design of NZMs with low-carbon-generation resources that are dispatchable as required for the sustained operations of the microgrid in islanded mode, configured in multiple ways to balance renewable energy resources

- Develop net-zero systems for specific applications for infrastructure electrification such as EV charging stations, airports, military installations, and net-zero community grids

- Develop a net-zero technoeconomic analysis platform to model and evaluate NZM for multiple use cases and applications for use by industry and the research community at large. 